\title{
LA NEUTRALIDAD DEL ESTADO Y EL PROBLEMA DEL GOVERNMENT SPEECH ${ }^{1}$ \\ The neutrality of the State and the problem of the government speech
}

\author{
VÍCTOR J. VÁZQUEZ ALONSO \\ Universidad de Sevilla \\ vvazquez@us.es
}

Cómo citar/Citation

Vázquez Alonso, V. J. (2017).

La neutralidad del Estado y el problema del government speech.

Revista de Estudios Políticos, 177, 13-55.

doi: https://doi.org/10.18042/cepc/rep.177.01

\section{Resumen}

La Corte Suprema norteamericana ha elaborado una doctrina sobre la neutralidad política de las instituciones públicas a través del concepto de government speech. La idea central de esta doctrina es que cuando el gobierno habla ideológicamente a través de sus políticas no está limitado por la Constitución y por lo tanto su único control no es judicial, sino el del proceso político. En este trabajo se va a estudiar la evolución jurisprudencial de esta doctrina, poniendo la atención en cómo el concepto constitucional de public forum opera como una suerte de límite interno a la idea de government speech. Del mismo modo, se verá cuáles han sido los criterios usados por la Corte Suprema para establecer límites tanto a la discrecionalidad estatal a la hora de discriminar por motivos ideológicos en sus políticas de gasto como al propio poder de recaudación estatal para financiar el discurso gubernamental. Finalmente, concluiremos con una reflexión en la que se pondrán de manifiesto algunas carencias de las que adolece la doctrina del government speech en un contexto donde, a través de Internet y el desarrollo de la web 2.0, la presencia y difusión del discurso gubernamental, y su interacción con los ciudadanos, ha cambiado radicalmente.

1 Agradezco al profesor Antonio Porras el haberme puesto en la pista de la jurisprudencia norteamericana de la que surge la idea de realizar este trabajo. Igualmente, he de agradecer a los profesores Emilio Guichot Reina, Miguel Álvarez Ortega, Germán Teruel y Andrés Boix Palop la lectura de su primera versión y sus muchas y acertadas sugerencias. 


\title{
Palabras clave
}

Neutralidad del Estado; libertad de expresión; acción de Gobierno; Estado social; control constitucional.

\begin{abstract}
The US Supreme Court has developed a doctrine on the political neutrality of public institutions, through the concept of "government speech". The central idea of this doctrine is that when the government talks ideologically, through its policies, it is not limited by the Constitution and therefore its control is not legal but through the political process. This paper studies the jurisprudential evolution of this doctrine, paying particular attention to how the constitutional concept "public forum" operates as an internal limit on the idea of government speech. Similarly, we focus attention on the criteria used by the Supreme Court to set limits on government discretion to discriminate, for ideological motives, in its public spending policies. Finally, we conclude with a reflection on the problems of this doctrine in a context where, through the internet and the development of web 2.0, the presence and dissemination of government speech and its interaction with citizens has changed radically.
\end{abstract}

\section{Keywords}

Neutrality; freedom of expression; government speech; welfare State; judicial review. 


\section{SUMARIO}

I. PLANTEAMIENTO DE LA CUESTIÓN: DE LA NEUTRALIDAD DE LA CONSTITUCIÓN A LA NEUTRALIDAD EN LA CONSTITUCIÓN. II. NEUTRALIDAD RELIGIOSA V. NEUTRALIDAD POLÍTICA EN LA PRIMERA ENMIENDA. III. LA DOCTRINA JUDICIAL DEL GOVERNMENT SPEECH: 1. El discurso del Estado y la libertad de expresión de los demás: al estado de Texas no le gusta la bandera confederada. 2. La doctrina del public forum como límite a la impunidad del gobierno políticamente no neutral. IV. CUANDO EL DISCURSO PAGA UNOS DISCURSOS Sí Y OTROS NO: EL «ESTADO PATRÓN» Y LA DOCTRINA DE LAS UNCONSTITUTIONAL CONDITIONS. V. CUANDO (TODOS) PAGAMOS EL DISCURSO QUE EL GOBIERNO QUIERE. VI. A MODO DE CONCLUSIÓN: RECAPITULACIÓN CRÍTICA A UN CONCEPTO JURÍDICO RAZONABLE. BIBLIOGRAFÍA.

\section{PLANTEAMIENTO DE LA CUESTIÓN: DE LA NEUTRALIDAD DE LA CONSTITUCIÓN A LA NEUTRALIDAD EN LA CONSTITUCIÓN}

Cuando discutimos sobre la noción de neutralidad del Estado o de las instituciones públicas podemos hacerlo desde, al menos, tres posiciones diferenciadas $^{2}$. Por un lado, desde una perspectiva, digamos iusfilosófica, el debate

2 Desde luego, esta reducción del debate sobre la neutralidad del Estado a tres perspectivas de análisis puede parecer en exceso simplista, si bien, como intentaré mostrar en adelante, creo que sí sirve para acotar el marco de análisis de este trabajo. Sobre las distintas acepciones de la idea de neutralidad política interior del Estado, creo que sigue vigente, y resulta exhaustiva, la que propusiera Carl Schmitt en el Defensor de la Constitución, quien diferenciaba, como es sabido, entre los significados negativos y positivos de la idea de neutralidad. Los primeros se caracterizarían porque aluden a la necesidad de evitar todo posicionamiento político de los poderes en ciertos ámbitos, y aquí podría encuadrarse la neutralidad entendida como imparcialidad, que sería la propia del Estado liberal frente a las diversas religiones, la del Estado técnico o burocrático frente a los administrados, y del mismo modo, aquella que se predica del proceso político democrático, en tanto sitúa de forma previa a todas las fuerzas políticas en un mismo punto de partida en relación a sus posibilidades de participar en la formación de la voluntad popular. La acepción positiva de la neutralidad estatal se expresaría, según Schmitt, cuando el tratamiento neutral se produce a través, no de una abstención, sino de una decisión del Estado. Tal sería el caso de la objetividad judicial en la aplicación de la ley, el de las decisiones que imponen la unidad en la 
se sitúa en torno a la idea de neutralidad liberal como categoría que subyace en la propia vocación universalista del constitucionalismo, lo cual nos reenvía a la ingente literatura jurídica crítica que, principalmente desde presupuestos comunitaristas, insiste en las contradicciones epistemológicas y en las propias patologías excluyentes de la «ilusión liberal» de un orden constitucional neutral frente a las distintas comprensiones de lo bueno y lo justo. En este plano de discusión, por lo tanto, la cuestión no es qué tipo o qué nivel de neutralidad impone una determinada constitución, sino más bien hasta qué punto el constitucionalismo liberal realmente descansa en una comprensión neutral frente a las distintas formas de vida que hoy integran las modernas sociedades democráticas o si esto no es más que una ilusión.

En segundo lugar, otro nivel de discusión sobre la neutralidad de las instituciones públicas puede situarse en el plano, digamos, exclusivamente político. Aceptando la idea de que un cierto grado de neutralidad frente a las distintas ideas de lo bueno y lo justo es, no ya una exigencia jurídica, sino un presupuesto moral para una integración armónica o igualitaria del pluralismo, uno puede discutir si determinada forma de actuar de los poderes públicos se desvía, no de lo jurídicamente prescrito, sino de un ideal que vincula los actos de las instituciones públicas con el máximo de imparcialidad o equidistancia ideológica posible, por lo menos desde un punto de vista, podríamos decir, simbólico. Nos moveríamos, en este plano, dentro de la crítica política e informal a quien, sin desviarse de sus obligaciones jurídicas, proyecta su ideología desde las instituciones hasta el punto de que ciertos ciudadanos se pueden ver menospreciados o excluidos de ellas.

Finalmente, un último nivel de discusión lo podríamos situar en las obligaciones, en este caso sí, estrictamente jurídicas, de equidistancia o imparcialidad que recaen en los poderes públicos y que tendrían su base en la propia constitución. Aquí sí nos encontramos ya dentro del debate sobre el alcance jurídico del principio de neutralidad del Estado. Pues bien, tomando como referencia la experiencia constitucional norteamericana, donde la discusión doctrinal y judicial es especialmente rica desde la primera finales de la década de los noventa, intentaremos abordar en este trabajo la problemática específica de cómo concretar las exigencias derivadas del principio de neutralidad estatal, través de un concepto original de la jurisprudencia norteamericana como es el de government speech. La idea central que se esconde tras este

resolución de pugnas en el interior del Estado, provocadas por el pluralismo de intereses, o aquella posición de equidistancia que se confía al asesor externo o extranjero, no implicado ni vinculado con los intereses que puedan estar en pugna en un determinado conflicto (Schmitt y Kelsen, 2009: 201, 207). 
concepto es la de que todo gobierno «habla», es decir «habla políticamente» ${ }^{3}$, y que el relato de su discurso no solo se deduce de sus palabras sino sobre todo de sus propias políticas. El gobierno, en definitiva, nos está diciendo qué ideas políticas quiere hacer realidad y cuáles desprecia, cuando hace declaraciones institucionales o comparecencias, pero también cuando promociona, subvenciona, discrimina... unas determinadas opciones frente a otras (Shiffrin, 1980: 565) ${ }^{4}$. Normalmente, en un Estado democrático, la ideología que impregna las políticas de un gobierno no va a ser sino aquella sobre la cual se construyó la oferta política que, de forma directa o indirecta, fue secundada por la ciudadanía a través del proceso electoral, y, por ello, la responsabilidad por las inclinaciones ideológicas de sus decisiones será una responsabilidad de naturaleza política, salvo que esas decisiones colisionen con alguna de las normas o reglas consagradas en la Constitución ${ }^{5}$.

Ahora bien, que el gobierno no esté obligado a ser ideológicamente neutral en su discurso no significa que pueda imponer a los ciudadanos que lo hagan suyo. En este sentido, los límites a la idea de government speech son fáciles de ver cuando el gobierno discrimina por la vía de prohibir, sancionar o

3 Una construcción clásica de la idea de los poderes del Estado - legislativo y ejecutivocomo poderes parciales, en tanto siempre vinculados a un interés, la podemos encontrar en Benjamin Constant, quien, como es sabido, desarrollaría sobre la base de esta parcialidad de los poderes políticos su teoría sobre la necesidad de un poder neutral que sería para él, el poder del monarca. No obstante, esta neutralidad a la que apela Constant no es tanto una neutralidad frente a los ciudadanos, sino frente a los propios poderes constituidos, y su finalidad inmediata no sería situar a los ciudadanos en un plano de igualdad frente al poder, sino la propia conservación del orden político y social, un punto en el que todos los actores políticos estarían de acuerdo, y sobre el que descansaría la propia legitimidad de la institución monárquica (Constant, 2013: 201). Sobre este último punto, es de especial interés el estudio de contextualización que lleva a cabo Eloy García, en el que se insiste en la vinculación lógica entre los conceptos de neutralidad, estabilidad y legitimidad, en la obra del pensador suizo.

4 Junto con Shiffrin, uno de los primeros autores que acuña el concepto de government speech es Mark G. Yudof, quien en un artículo explora la difícil relación entre el discurso político, por definición ideologizado, con los valores que se derivan de la Enmienda XIV (Yudof, 1979: 865). Partiendo de la tesis del inevitable carácter no neutral del discurso político, Yudof escribirá la primera monografía que aborda en profundidad el concepto de government speech bastantes años antes de que la propia Corte Constitucional lo hiciera suyo (Yudof, 1983).

5 Por ejemplo, una política que establezca diferenciaciones que no superen el parámetro de control de la equal protection clause será también una política no neutral, lo cual no quiere decir que toda desviación de la neutralidad por parte de las instituciones públicas se sitúe al margen de la Constitución. 
imponer. Sin embargo, la cuestión es mucho más compleja cuando las diferenciaciones en el trato no se establecen por la vía de prohibir sino por la vía de subvencionar ${ }^{6}$. Desde luego, hay muchos ámbitos en los cuales a los poderes públicos no les hace falta acudir a prohibiciones para conseguir que determinadas opciones privadas se vean favorecidas frente a otras. En este sentido, del mismo modo que el gasto público es quizá el mejor relato o la mejor huella del discurso ideológico real de un determinado gobierno, también es cierto, como podremos ver, que la diferenciación entre el incentivo económico y la coacción no es siempre algo fácil de determinar.

Igualmente, no puede obviarse que el Estado, además de disponer de unos canales de comunicación institucional específicos, posee también «un prestigio» frente a muchos ciudadanos y que, en este sentido, el discurso institucional tiene una posibilidad real de incidir y modificar el equilibrio que pudiera haber resultado en la opinión pública como consecuencia del free market of ideas al que aspira una sociedad liberal. Del mismo modo, cuando el gobierno «habla», en muchas ocasiones no lo hace solo, sino que lo hace con la cooperación de la sociedad, o mejor dicho, de algunos sectores de la sociedad y en detrimento de otros, no siendo siempre fácil distinguir hasta qué punto nos encontramos ante un discurso de naturaleza pública, de naturaleza privada o híbrido (Corbin, 2008).

En definitiva, si bien puede parecer evidente que todo gobierno ha de poder articular un discurso ideológico a través de sus actos, es mucho más complejo determinar qué límites constitucionales puede encontrar este concepto de government speech. La Corte Suprema norteamericana se ha enfrentado a esta cuestión, en realidad latente en cualquier ordenamiento constitucional pluralista, a través de una jurisprudencia que nos servirá de hilo conductor en este trabajo. Así, primeramente, trazaremos la distinción entre el concepto de neutralidad religiosa y neutralidad política en la Primera Enmienda de la Constitución norteamericana y la importancia que tiene el propio concepto de government speech en la misma. Posteriormente, estudiaremos los perfiles jurídicos de este concepto a la luz de la reciente sentencia de la Corte Suprema en relación a la prohibición de la exhibición de la bandera confederada en los coches matriculados en el estado de Texas. Luego,

6 Una idea ya desarrollada, en la década de los setenta, por constitucionalistas como Tribe, quien, en un trabajo pionero, ya establecía las diferencias en el tratamiento jurídico del gobierno cuando actúa como «censor» a cuando actúa como "patrón» en los siguientes términos: "Nor can an acceptable free speech theory demand that government be an ideological eunuch; the theory must be subtle enough to distinguish government as censor from government as speaker» (Tribe, 1978: 244). 
prestaremos atención a cómo el concepto constitucional de public forum opera como una suerte de límite interno a la idea de government speech. Del mismo modo, veremos cuáles han sido los criterios de la Corte Suprema para establecer límites tanto a la discrecionalidad estatal a la hora de discriminar por motivos ideológicos en sus políticas de gasto como al propio poder de recaudación estatal para financiar el discurso gubernamental. Finalmente, concluiremos con una reflexión crítica, donde se pondrán de manifiesto algunas carencias de las que adolece la idea de government speech en un contexto donde, a través de Internet y el desarrollo de la web 2.0, la presencia y difusión del discurso gubernamental, y su interacción con los ciudadanos, ha cambiado radicalmente; y donde intentaremos también, desde la perspectiva de un ordenamiento mucho menos «indiferente en valores» como el español, subrayar los matices con los que puede traducirse este concepto.

\section{NEUTRALIDAD RELIGIOSA V. NEUTRALIDAD POLÍTICA EN LA PRIMERA ENMIENDA}

A finales de los ochenta, el profesor Robert D. Kamenshine defendió una tesis que creo que nadie ha vuelto a defender, por lo menos con tanta claridad, en la doctrina norteamericana: que la Primera Enmienda prohíbe no solo el Religious Establishment sino también el Political Establishment (Kamenshine, 1979). Como es sabido, la Primera Enmienda establece un principio de neutralidad religiosa a través del enunciado Congress shall make no law respecting an establishment of religion, sin que podamos encontrar en este artículo ningún mandato de neutralidad política equivalente. Lo que sí hay en esta Primera Enmienda es un reconocimiento específico del derecho a la libertad de expresión, del cual Kamenshine quiere deducir esta Implied Political Establishment Clause que impondría a los poderes públicos un cierto nivel de neutralidad ideológica en sus políticas institucionales.

El alcance del mandato de neutralidad religiosa a los poderes públicos derivado de la Establishment Clause es una de las cuestiones más debatidas y polémicas dentro de la doctrina y la propia práctica judicial norteamericana, si bien, desde la década de los cincuenta, que es cuando la Supreme Court proyecta por primera vez esta cláusula sobre la legislación de los estados, puede decirse que en el ordenamiento norteamericano los poderes públicos están obligados a realizar en materia religiosa políticas guiadas por una estricta neutralidad con respecto a las diferentes confesiones. Dicho de otra forma, la Constitución veda de forma clara la posibilidad de que exista un religious government speech. De hecho, el principal test de constitucionalidad manejado por la Corte Suprema norteamericana en aplicación de la Establishment Clause, 
el Lemon Test ${ }^{7}$, impone una neutralidad tanto en los propósitos de la legislación como en los efectos de su aplicación, e, incluso, una neutralidad digamos simbólica, que veda cualquier enmarañamiento (entanglement) entre el Estado y la religión.

La cuestión es, en este sentido, si este principio de neutralidad religiosa puede ser proyectado de forma análoga al terreno ideológico. $\mathrm{O}$ dicho de otra forma, si un esquema analítico similar al de la Establishment Clause puede trasladarse al ámbito estrictamente político. Lo cierto es que trasladar los principios que definen la relación del Estado con el fenómeno religioso a la esfera política se enfrenta a problemas insuperables. Como reconoce el propio Kamenshine, cualquier equiparación de la neutralidad religiosa del Estado con la neutralidad ideológica no puede obviar una diferencia insalvable, que es la de que, si bien el Estado puede funcionar sin estar bajo el control de las asociaciones religiosas, esto no es en ningún caso extensible a las asociaciones políticas, ya que son estas, en definitiva, las que hacen funcionar al Estado y las que han de controlar el propio proceso democrático ${ }^{8}$. Dicho de otra forma, la religión es una cuestión constitucionalmente diferente a la ideología y el afán profiláctico para con la primera no puede extenderse en ningún caso a la segunda, puesto que los actos a través de los cuales se expresa el Estado son actos en los que subyace una decisión política'. Sin embargo, el hecho de que no pueda ser asimilable el estricto umbral de la neutralidad religiosa del Estado al de la neutralidad política no significa necesariamente que este segundo principio no constituya también un límite a la actividad del gobierno. Para Kamenshine, el límite se encontraría en aquellas políticas que, desde el gobierno, rompen el fair play democrático, al utilizar los recursos y la propia visibilidad de las instituciones democráticas para promocionar en la sociedad visiones ideológicas afines y silenciar o, indirectamente, coaccionar las voces críticas. Por lo tanto, pese a que es inevitable que el gobierno actúe políticamente, o, si se prefiere, es consustancial a la propia democracia la idea de government speech, esta tendría un límite en el principio jurídico non political establishment, que vendría a prohibir the government advocacy of political viewpoints and unequal government assistance to private political dissemination (Kamenshine, 1979: 1120, 1121).

Pese a que pueda haber razones que inviten a desarrollar una doctrina judicial de los límites al government speech basada, tal y como proponía

Lemon v. Kurtzman, 403 U.S. 602 (1971).

8 «A democratic form of government can operate without controlling or being controlled by religious groups. The same is not true, however, with politics. The political process must control the government if a democratic system is to survive» (Kamenshine, 1979: 1119).

9 Sobre esta diferenciación me he ocupado, en extenso, en Vázquez Alonso (2015). 
Kamenshine, en la idea de que la Constitución impone al gobierno el mínimo de neutralidad política necesaria para que no se vea adulterado el debate ideológico en la sociedad, lo cierto es que la jurisprudencia de la Corte Suprema ha construido la categoría de government speech no sobre este principio de la neutralidad política, sino sobre uno que opera de forma contraria. El punto de partida de esta jurisprudencia es Rust v. Sullivan ${ }^{10}$, una sentencia en la que la Corte Suprema considera que la Primera Enmienda no impide que el Estado limite el ámbito de beneficiarios de un plan estatal de planificación familiar a aquellas clínicas que no contemplan el aborto como una medida de planificación. Sin aludir expresamente al término government speech, la mayoría de la Corte entiende que el gobierno no actúa al margen de la Constitución cuando, sobre la base de sus preferencias ideológicas, promociona ciertos objetivos en detrimento de otros ${ }^{11}$. En definitiva, desde la década de los noventa el principio que se abre paso en el Tribunal es el de que la inclinación ideológica de un gobierno, por muy obscena que sea para algunos, no puede ser fiscalizada judicialmente desde la Constitución por su falta de neutralidad, sino a través del proceso político y, en último caso, ante el electorado. Dicho de forma clara, "cuando el gobierno habla, para promocionar sus propias políticas o sus ideas particulares, en último término sólo es responsable democráticamente» ${ }^{12}$.

Obviamente, cuando se protege el discurso del gobierno no se hace sobre la base de que este tenga una mayor dignidad, ni incluso la misma dignidad a la que parte de la doctrina norteamericana vincula el valor preferente que se da a la protección de la libertad de expresión en este ordenamiento $^{13}$. Como ha señalado algún autor, el concepto jurídico de government speech lo que en realidad hace es poner de manifiesto una preferencia judicial en este ámbito por los principios democráticos frente a los igualitarios (Park, 2010: 145); todo ello a partir de la idea de que los órganos de gobierno han de ser "receptivos al deseo mayoritario del pueblo» ${ }^{14} \mathrm{y}$ esto conlleva una inevitable falta de equidistancia con las opiniones políticas derrotadas en el proceso electoral ${ }^{15}$.

10 Rust v. Sullivan, 500 U.S. 173 (1991).

11 Rust v. Sullivan, 500 U.S. 173, 194 (1991).

12 Board of regents of the University of Wisconsin System v. Southworth, 529 U.S. 217, 235 (2000).

13 Como bien resume Bezanson, existe una idea compartida de que "government is a speaker that enjoys no individual liberty or free will, and whose need to express itself is limited by a different constitutional role and duty» (2010: 816).

14 Stromber v. California, 283 U.S. 359, 369 (1931).

15 «The first amendment does not mandate a view point neutral government. Government must choose between rival ideas and adopt some as its own; competition 
En cualquier caso, aun partiendo de este presupuesto democrático, esta tesis se enfrenta, más aún en un ordenamiento como el norteamericano, donde la libertad de expresión ocupa un lugar central, a un problema ineludible, que es el de cómo conciliar el principio de que el gobierno solo es responsable de su discurso ante el electorado con otros dos principios constitucionales, en principio irrenunciables, como son que «el gobierno no puede imponer a la gente lo que ha de decir» ${ }^{16}$ ni tampoco discriminar a los ciudadanos a partir de consideraciones sobre su ideología u orientación política. Como dijera el juez Jackson en su conocida opinión en Barnette:

[...] si hay una estrella fija en nuestra constelación constitucional, esa es la que dice que ningún funcionario o autoridad pública, de cualquier rango, puede prescribir cuál debe de ser la ortodoxia en materia política, nacional, de religión, o en cualquier otro ámbito ideológico, de la misma forma que no puede forzar a los ciudadanos a confesar a través de sus palabras o de sus actos qué fe profesan ${ }^{17}$.

Hay, por lo tanto, una tensión entre el ideal democrático que se esconde detrás del concepto de government speech, y el principio liberal e igualitario, que se encuentra arraigado en la cultura constitucional y la propia doctrina judicial de la Corte Suprema ${ }^{18}$. Veamos cuál ha sido la forma a través de la cual la Corte Suprema ha intentado conciliar ambos principios.

\section{LA DOCTRINA JUDICIAL DEL GOVERNMENT SPEECH}

\section{EL DISCURSO DEL ESTADO Y LA LIBERTAD DE EXPRESIÓN DE LOS DEMÁS: AL ESTADO DE TEXAS NO LE GUSTA LA BANDERA CONFEDERADA}

En fechas recientes, la Corte Suprema ha tenido la oportunidad de sintetizar su doctrina sobre el government speech en una sentencia singularmente

over cartels, solar energy over coal, and weapon development over disarmament... Moreover, the government may enlist the assistance of those who believe in its ideas to carry then for fruition; and it need not enlist for that purpose those who oppose or do not support the ideas..." (Scalia, dissenting), Agency for Int'l Dev. v. Alliance for Open Soc'y Int'l, Inc. 570 U.S. (2013).

16 Runsfeld v. Forum for Academic and Institutional Rights, Inc., 547 U.S. 47, 61.

17 West Virginia State Board of Education v. Barnette, 319 U.S. 624, 642 (1943).

18 Entre otros, para un planteamiento exhaustivo de este conflicto, con una buena síntesis de las voces doctrinales críticas, véase Blocher (2011). 
mediática ${ }^{19}$ donde, por una mayoría de cinco contra cuatro, ha fallado que el estado de Texas no había vulnerado la Primera Enmienda de la Constitución al no autorizar la petición de la asociación de hijos de soldados confederados para que la bandera confederada pudiese ser exhibida en las matrículas de los coches del Estado por quien así lo desease ${ }^{20}$. La cuestión de fondo en este litigio no es, obviamente, si un ciudadano puede o no exhibir la bandera confederada; en el ordenamiento norteamericano, la exhibición no solo de este símbolo político sino de cualquiera otro, por muy extremo que entendamos que es, está amparada por la libertad de expresión ${ }^{21}$. Tampoco se trata de

19 La dimensión mediática que adquiere esta sentencia, más allá de por la relevancia del fallo sobre una cuestión especialmente delicada en la sociedad norteamericana, como es la de la simbología evocadora de la Guerra Civil y de la esclavitud, tiene que ver con el hecho de que, un día antes de hacerse pública la decisión, se producía una masacre en la ciudad de Charleston, en Carolina del Sur, con el asalto armado a la Emmanuel African Methodist Episcopal Church, en el que mueren nueve miembros de esa comunidad, todos ellos afroamericanos. Tras estos hechos, la bandera confederada, oficial en el estado de Carolina del Sur, ondeó a media asta en los edificios del Parlamento y del gobierno del estado, lo que provocó una oleada de indignación por parte de unos ciudadanos que habían podido ver anteriormente diversas fotos, difundidas por los medios de comunicación, del autor de la matanza ondeando esta enseña. En último término, el movimiento de protesta ciudadano provocó que el Senado de Carolina del Sur decidiera retirar la bandera confederada, y que en este estado y también en los estados de Maryland y de Virginia se iniciaran reformas legislativas para eliminar este símbolo de entre aquellos por los que los ciudadanos pueden optar como fondo para la matrícula de sus vehículos.

20 Walker v. Texas Division, Sons of Confederate Veterans, 576 U.S. (2015). La variedad de diseños de matrículas entre las que pueden elegir los ciudadanos de Texas tiene tres fuentes diversas. Por un lado, la propia Asamblea legislativa del Estado puede aprobar diversos diseños con lemas o motivos que considere ayudan a trasmitir ciertos valores que identifican al Estado. Al mismo tiempo, la legislación texana crea un órgano administrativo encargado de aprobar los diseños presentados por vendedores privados a los que se les adjudica esta concesión y que, a su vez, van a trabajar en diseños que los ciudadanos u organizaciones les sugieren. Finalmente, este órgano administrativo puede crear por sí mismo nuevos diseños o aprobar algunos diseños presentados por entidades sin ánimo de lucro. Este último sería el supuesto que dio lugar al litigio que aquí analizamos.

21 Como ejemplos paradigmáticos de protección del discurso extremo bajo la Primera Enmienda son conocidas las decisiones de la Corte Suprema en R.A.V. v. City of S. Paul (1992), en la cual la Corte considera que está amparada por la libertad de expresión la quema de una cruz frente a la casa de una familia afroamericana; o la igualmente polémica Smith v. Collin 439 U.S. 916 (1978), donde la Corte se pronuncia sobre la conocida 
juzgar si los ciudadanos tienen derecho o no a que el Estado incorpore en una placa oficial que sirve tanto de licencia como de identificación - como es una matrícula de automóvil- la simbología que ellos estimen. La cuestión que late aquí no es otra que la de determinar si una vez que el Estado permite que los ciudadanos usen una plataforma pública para comunicar mensajes privados, este puede discriminar, permitiendo la difusión de unos mensajes y rechazando otros. Más en concreto, como ya puede intuirse, el elemento clave en este litigio es si puede o no considerarse que el Estado, al elegir qué mensajes se podrán exhibir en sus matrículas, está definiendo su propio discurso y, por lo tanto, no está sujeto a otro control que el del proceso político ${ }^{22}$.

El problema en Walker v. Texas Division, Sons of Confederate Veterans es que no es solo el gobierno quien habla a través de las matrículas, sino que en la conformación de este discurso participan selectivamente y de forma coral algunos ciudadanos, lo que, en último término, pone en cuestión si es realmente un supuesto de government speech o más bien un supuesto por lo menos híbrido $^{23}$, en tanto afecta también a la libertad de expresión de los ciudadanos, y donde, por lo tanto, lejos de aplicarse la doctrina en virtud de la cual, «si es el gobierno el que habla no está prohibido por la Primera Enmienda que

marcha de Skokie, en la que unos nazis pasearon frente a un barrio de judíos, muchos de ellos víctimas o descendientes de víctimas de la Shoah, confirmando su protección constitucional. Del mismo modo, es conocida la doctrina de la Corte Suprema respecto a la cuestión de la flag desacration invalidando la tipificación penal de la quema de la bandera nacional hasta entonces vigente en el estado de Texas: Texas $v$. Johnson 491 US 397 (1989). Dentro de la ingente doctrina norteamericana sobre la cuestión del hate speech o extreme speech, una visión exhaustiva y al mismo tiempo crítica de la jurisprudencia la podemos ver en Waldron (2012). Sobre la diferente comprensión de los límites de la libertad de expresión en este ámbito y dentro de la doctrina española pueden verse, entre otros, Alcacer Guirao (2015: 56-67), Revenga Sánchez (2015: 15-32). Y en la italiana, insistiendo en la necesidad de evitar cualquier límite al discurso público para garantizar el potencial integrador de la comunidad política, puede verse Caruso (2013).

Se debe aclarar que por proceso político en este contexto no debe entenderse aquí únicamente los mecanismos institucionales de control de la acción de gobierno previstos, o, en último término, los diferentes procesos electorales, sino que hay que entenderlo en un sentido amplio, integrando todas las formas de presión que se pueden ejercer desde la sociedad para exigir responsabilidades al poder, desde muy diversas esferas, como la prensa, los lobbies y grupos de presión, las asociaciones cívicas...

23 La principal defensa doctrinal de la necesidad de comprender ciertos supuestos como mixed speech la podemos encontrar en el ya citado trabajo de la profesora Corbin (2008: 607 y ss., en especial), y también en la nota publicada por la Harvard Law Review sobre esta cuestión en 2011 (HLR, 2011: 806 y ss.) 
determine el contenido de lo que dice» ${ }^{24}$, habría, por el contrario, que aplicar la muy estricta doctrina judicial sobre los límites estatales al discurso pri$v a^{25}$. En definitiva, la cuestión clave en el juicio de la Corte era determinar si puede seguir aplicándose la teoría del government speech a aquellos supuestos en los que el gobierno hace un escrutinio entre los discursos privados, discriminando a favor de los afines. Sobre esta cuestión, la Corte Suprema disponía de un precedente relativamente cercano aunque no del todo análogo. En el año 2009 el Tribunal entendió de forma unánime que la ciudad de Pleasant Grove City no había vulnerado la Primera Enmienda de la Constitución al haber rechazado la donación hecha por una asociación religiosa de una escultura de naturaleza confesional destinada a ser ubicada en un parque público en el que se exhibían diversos monumentos donados por otras asociaciones privadas $^{26}$, incluido uno de inequívoco carácter religioso como es la tabla de los Diez Mandamientos. Para la Corte se trataba de un caso de government speech y, por lo tanto, no debía de ser sometido al estricto escrutinio que exige cualquier limitación a la libertad de expresión. Para llegar a esta conclusión el Tribunal apela a un factor cultural: existe una tradición en Norteamérica de abrir este tipo de espacios públicos a donaciones de los ciudadanos, pero siempre con un previo proceso de selección por parte de la autoridad gubernativa, al entenderse que los ciudadanos, cuando ven un determinado monumento en un espacio público, consideran que, aun proviniendo de manos privadas, este monumento está ahí porque las autoridades públicas así lo han querido ${ }^{27}$. Lo determinante para la mayoría del Tribunal es, en definitiva, que el Estado

24 Pleasant Grove City v. Summun 555 U.S. 460, 467-468 (2009).

25 Es de esta última forma como lo entendió la Corte de Apelaciones del Quinto Circuito, quien sostuvo que el diseño de matrículas era una manifestación privada de la libertad de expresión y que, por lo tanto, la decisión de las autoridades de Texas de prohibir el uso de la bandera confederada constituía un supuesto de censura ideológica — view point discrimination - siempre prohibido por la Primera Enmienda de la Constitución, Texas Div., Sons of Confederate Veterans, Inc., v. Vandergriff, 759 F. 3d 388, 397 (2014).

26 Pleasant Grove City v. Summun 555 U.S. 460, 467-468 (2009).

27 La Corte falla en Summun por unanimidad, de lo cual podría deducirse que se trata de un caso fácil. Sin embargo, la interpretación del Tribunal ha provocado dudas y despertado críticas en la doctrina, no por tanto por cómo se proyecta la doctrina del government speech, sino por el hecho de que el Tribunal no afronta en su razonamiento los problemas que la decisión del municipio podía plantear desde la perspectiva de la Establishment Clause, es decir, no desde la neutralidad política sino desde la neutralidad religiosa. La estricta neutralidad hacia las distintas religiones se encuentra, en este sentido, en el corazón de la interpretación que la Corte ha dado a esta cláusula, y no 
tiene en todo momento el control de lo que se dice a través de un espacio que está bajo su dominio, de tal forma que los ciudadanos van a interpretar que es el propio Estado quien en último término habla ${ }^{28}$.

Pues bien, este mismo razonamiento, centrado en la determinación de quién es en último término el que controla el mensaje, es el que va a servir de fundamento para la mayoría del Tribunal en Walker v. Texas Division. Tomando en consideración, igualmente, la cultura política norteamericana, la Corte constata que, desde principios del siglo $\mathrm{xx}$, los estados han usado las matrículas de los coches para transmitir ciertos mensajes con los que quieren que se les relacione, y que, por ello, estas pueden considerarse una suerte de documento de identidad de los propios estados. Por lo tanto, es por esta relación de identidad por lo que resulta lógico que un estado pueda excluir aquellos mensajes propuestos por la ciudadanía con los que él no quiera identificarse ${ }^{29}$. En definitiva, quien quiera que su mensaje sea integrado en una matrícula tendrá que buscar uno que concuerde con aquellos valores o ideas que el estado quiere transmitir, porque, al fin y al cabo, es el estado quien decide cómo se presenta a sí mismo. A este respecto, la Corte deduce, al final de su razonamiento, un principio que tiene un cierto afán sintetizador de su jurisprudencia y que vendría a decir: igual que el estado no puede imponer al ciudadano lo que tiene que decir, ninguna asociación puede obligarle a él a que haga suyo un discurso con el que no está de acuerdo ${ }^{30}$.

parece fácil conciliar ese principio con el hecho de que el Estado permita que una simbología religiosa tenga acceso al dominio público y otra no (Garry, 2009).

Hasta el punto, insiste la sentencia, de que los propios monumentos que allí se exhiben pierden en muchos casos el significado original que estos tenían para los donantes, y adquieren uno nuevo, resultante de la convivencia con otros símbolos también seleccionados por el Estado para ser exhibidos en el mismo lugar, y de la propia lectura que desde el poder se quiere hacer de ellos A este respecto, entre otros ejemplos, la sentencia apela al evidente cambio de significado que ha experimentado la Estatua de la Libertad, donada por la III República francesa, como un símbolo de la amistad y de la alianza entre las dos naciones y después transformada en una alegoría de la apertura de los Estados Unidos de América a los inmigrantes que llegaban en busca de un futuro en libertad dentro de sus fronteras, Pleasant Grove City v. Summun 555 U.S. 460, 475 (2009). Insistiendo en la imposibilidad de ceñir a un criterio de neutralidad ideológica el tratamiento estatal de la simbología pública, puede verse Levinson (1995).

Entre los autores que antes de la sentencia ya habían defendido que necesariamente el concepto jurídico de government speech ha de integrar la libertad del poder político para poder discriminar entre discursos privados, allí donde el discurso de las instituciones y el de los ciudadanos confluyan, puede verse Norton (2004).

La Corte aquí no hace sino deducir un significado sensu contrario al principio establecido en Wooley de que la Primera Enmienda no perminte que el gobierno 
Como años antes había señalado algún autor, lo que esta jurisprudencia en realidad parece confirmar es que el Estado tiene el monopolio de su propio foro (Bezanson, 2010: 810-812), de tal forma que en este ámbito no está obligado por la Primera Enmienda a tolerar ningún discurso rival. Sin embargo, este principio, como habrá podido intuirse, requiere de un elemento de corrección, pues existen muchos ámbitos bajo la propiedad o control del Estado que son a su vez foros públicos tradicionalmente usados por los ciudadanos para su expresarse libremente. La idea de foro público, como veremos en el siguiente epígrafe, va a operar así como una suerte de límite interno a una doctrina como la del government speech que prescribe la impunidad jurídica del Estado por la falta de neutralidad de su discurso.

\section{LA DOCTRINA DEL PUBLIC FORUM COMO LÍMITE A LA IMPUNIDAD DEL GOBIERNO POLÍTICAMENTE NO NEUTRAL}

En la década de los treinta irrumpe en la jurisprudencia de la Corte Suprema el concepto jurídico de public forum, a través del cual los jueces norteamericanos han dado respuesta a la cuestión de hasta qué punto el Estado se halla vinculado a la Primera Enmienda en aquellos espacios públicos bajo su dominio que tradicionalmente han servido como foros de discusión ciudadana. En realidad, para encontrar la primera decisión judicial relevante sobre esta cuestión debemos remontarnos a una opinión de Oliver Wendell Holmes, todavía como juez de la Corte de Massachusetts, a través de la cual se dicta sentencia en el litigio Commonwealth $v$. Davis ${ }^{31}$, un caso en el que la Corte estatal se enfrentaba a la demanda de un predicador que había sido condenado por predicar en el Boston Common sin previo permiso de la autoridad municipal, lo que en su opinión constituía una vulneración de la Primera Enmienda de la Constitución federal. Frente a esta demanda, la respuesta de Holmes fue tan clara como afirmar que en los espacios públicos bajo su dominio, el gobierno dispone de la misma discrecionalidad para imponer restricciones que la de cualquier ciudadano en sus propiedades ${ }^{32}$. Una idea que va a

«require an individual to participate in the dissemination of an ideological message by displaying it on his private property in a manner and for the express purpose that it be observed and read by the public», Wooley v. Maynard, 430 U.S. 705, 713 (1977).

Commonwealth v. Davis, 39 N.E. 113 (Mass. 1895).

32 En concreto, para Holmes, «for the Legislature absolutely or conditionally to forbid public speaking in a highway or public park is no more an infringement of the rights of a member of the public than for the owner of a private house to forbid it in his house». Como señala Edward White, la idea de Holmes, y, en realidad, de la propia doctrina judicial mayoritaria en aquel entonces, acerca de los límites que el poder 
reafirmar posteriormente la propia Corte Suprema ${ }^{33}$, en la cual aún no se había consolidado una doctrina de la incorporación de la Primera Enmienda a los estados a través de la Enmienda Catorce, y en la que seguía presente una suerte de culto al derecho común británico, en detrimento de la eficacia directa de la Constitución, que precisamente jueces como Holmes contribuirán a erradicar posteriormente.

En cualquier caso, esta interpretación, como ha señalado algún autor, casi marcial de la libertad de expresión en el ámbito público, que legitimaba a los poderes públicos para hacer en calles, plazas y parques aquello que la Primera Enmienda prohíbe, es decir, silenciar los discursos privados, estaba destinada a ser derogada, no solo por la propia inercia liberal que se genera en la Corte según se va afianzando la idea de la vinculación de los estados a la Primera Enmienda, sino, sobre todo, porque la misma en buena medida negaba una realidad histórica, como era que ciertos espacios públicos habían sido considerados desde la América temprana como lugares abiertos para la libre discusión ideológica y también para el proselitismo religioso. Así, ya en 1939, en Hague v. C. I. O, un litigio donde la Corte enjuicia la constitucionalidad de una de las denominadas anti-picketing laws, en este caso de la ciudad de Jersey, con la que se quería impedir la libertad de los trabajadores para manifestar públicamente sus ideas y reivindicaciones en el espacio público, la mayoría del Tribunal se aparta de la doctrina establecida en Davis y afirma el principio contrario de que en determinados espacios públicos bajo su dominio, como calles y parques ${ }^{34}$, tradicionalmente abiertos a los ciudadanos para la libre

público puede imponer a la libertad de expresión de sus ciudadanos en sus propiedades o en cualquier el ámbito de su administración, puede apreciarse de una forma aún más nítida, en la opinión que el propio Holmes, también como juez de la Corte de Massachusetts, hace valer en el caso McAuliffev. Mayor of New Bedford, 29 N.E. 517 (Mass. 1892), donde sostiene que el despido de un bombero municipal como consecuencia de su participación en una campaña política no vulnera la Primera Enmienda de la Constitución, porque esta no protege ningún derecho a expresarse libremente en tanto empleado público.

Davis v. Massachusetts, 167 U.S. 43 (1897).

34 En realidad, más que una derogación integral de la doctrina Davis, en Hague v. C.I.O la Corte lleva a cabo una derogación parcial, extendiendo la eficacia de la Primera Enmienda a dos ámbitos públicos concretos como son las calles y los parques; si bien, con esta sentencia, como veremos en adelante, se sientan las bases para una doctrina, la de del public forum, que a través de diversos litigios se va a extender a otros ámbitos de la propiedad estatal que van más allá de estos que podemos considerar tradicionalmente vinculados a la discusión pública y la libre transmisión de ideas (Sullivan y Feldman, 2013: 274-283). 
expresión de sus ideas ${ }^{35}$, el estado está vinculado a las exigencias constitucionales de la Primera Enmienda ${ }^{36}$.

Como decíamos, esta forma de entender la libertad de expresión resulta mucho más acorde con el desarrollo de la cultura jurídica americana en el siglo Xx, pero también con los propios orígenes intelectuales de la Primera Enmienda que confluyen, en este caso, en un mismo paradigma permisivo. En este sentido, más allá de la idea liberal clásica de libertad de expresión, el propio sustrato de republicanismo cívico que subyace en la Primera Enmienda es inseparable de comprensión del foro público como ámbito deliberativo; de la misma forma que para la tradición evangelista no es admisible un concepto de libertad que no integre la posibilidad de realizar actos de proselitismo y evangelización en lugares públicos (De Wolfe Howe, 1965: 8). De hecho, la propia casuística judicial de la Primera Enmienda vinculada a la idea de foro público tuvo durante el siglo XX como protagonistas sucesivos a colectivos representativos de estas diversas tradiciones, de tal forma que si, en un principio, fueron las demandas evangelistas las que dieron pie al desarrollo de esta doctrina judicial, a partir de los años cincuenta, y de la Civil Rights Revolution, la lucha por la libertad de expresión en el espacio público ha estado principalmente vinculada a la participación política y al activismo de los derechos fundamentales por parte de ciertas minorías (Sullivan y Feldman, 2013: 272). En cualquier caso, de esta ingente jurisprudencia que, más allá de parques y calles, se ha proyectado sobre otros espacios públicos donde los ciudadanos han querido hacer valer el derecho a manifestar su opinión, como universidades, escuelas, aeropuertos o servicios postales..., puede deducirse un esquema analítico bastante nítido del concepto jurídico de public forum. Así, la Corte ha distinguido entre ${ }^{37}$ :

35 El origen de la categoría de public forum se suele vincular a la opinión del juez Roberts en esta sentencia, y en concreto, al siguiente obiter dicta: "Wherever the title of streets and parks may rest, they have immemorially been held in trust for the use of the public and, time out of mind, have been used for purposes of assembly... and discussing public question. Such use of the streets and public places has, from ancient times, been a part of the privileges, immunities, rights, liberties of citizens. The privilege of a citizen of the United States to use the streets and parks for communication of views on national questions may be regulated in the interest of all... but it must not, in the guise of regulation, be abridged or denied», Hague v. C.I.O., 307 U.S. 496, 515 (1939).

36 Para una lectura contemporánea de esta sentencia, insistiendo en el cambio de doctrina que se consolida con ella dentro del Tribunal en relación con Davis, puede verse Frank (1940: 279-280).

37 Walker v. Texas Division, Sons of Confederate Veterans, 576 U.S. 5, 13-15 (2015). 
- los foros públicos tradicionales, como calles y parques, que siempre han estado abiertos a que los ciudadanos puedan hacer uso de ellos para expresar sus opiniones, y, donde, por lo tanto, el Estado no puede imponer más límites a la libertad de expresión que los que estén justificados en un interés apremiante;

— los foros públicos habilitados como tales por el Estado — designated public forum - , que serían aquellos espacios de titularidad pública que han sido específicamente destinados al libre intercambio de ideas entre los ciudadanos. En estos ámbitos de propiedad pública, el Estado, igualmente, solo podrá restringir el discurso de los ciudadanos cuando esgrima un interés público apremiante que lo justifique;

- y, finalmente, la jurisprudencia de la Corte Suprema ha distinguido una tercera categoría, el non public forum, que la integrarían aquellas propiedades de dominio estatal que ni por tradición ni tampoco de forma premeditada han sido designadas como lugares para la discusión ciudadana. En este caso, los límites que el Estado quiera imponer sobre la libertad de expresión a aquellos ciudadanos que quieran acceder a estos ámbitos, únicamente tendrán que superar un test de razonabilidad, sin que, por lo tanto, el Estado tenga la carga de demostrar la existencia de un interés apremiante que legitime su política.

Reconduciendo el debate a la cuestión que nos ocupa, que es la de los límites constitucionales al discurso gubernamental, parece claro que en aquellos ámbitos públicos tradicionalmente abiertos a la discusión ciudadana, o en aquellos espacios que el Estado ha habilitado a tal efecto, no puede aplicarse el principio de que cuando el gobierno habla no está sujeto a límite jurídico alguno sino únicamente a los mecanismos de control y censura propios del proceso político. Donde haya un foro público, por el contrario, el Estado deberá mantenerse neutral con respecto a los distintos puntos de vista que allí quieran expresarse, de tal forma que solo cuando exista un interés estatal apremiante que lo justifique podrá imponer límites a la libertad de expresión.

El voto particular que suscriben tres magistrados a Walker v. Texas Division puede servirnos para poner de manifiesto la relevancia práctica de esta cuestión. Paradójicamente, la opinión discrepante la escribe el juez Alito, quien fue también el juez que redactó la opinión de la mayoría en Summun, el precedente al que, como acabamos de ver, acude la Corte en Walker v. Texas Division para descartar que al no autorizar la bandera confederada en las matrículas se haya vulnerado la Primera Enmienda de la Constitución. Para el juez Alito, la mayoría del Tribunal habría errado al considerar que el precedente a aplicar, en este supuesto, es aquel establecido en Summun, en virtud del cual «cuando el gobierno habla es libre para elegir el mensaje que quiere expresar». El precedente que procedía aplicar, en su opinión, era aquel 
establecido en Rosemberger $v$. Rector and Visitors, en virtud del cual, «en el ámbito de la libertad de expresión, la regulación del gobierno no debe favorecer unos discursos frente a otros». El origen de la sentencia Rosemberger se encuentra en el rechazo de las autoridades de la Universidad de Virginia a incluir a una asociación universitaria de sesgo religioso dentro de un programa de ayudas a la financiación de las publicaciones elaboradas por sus organizaciones de estudiantes. El motivo esgrimido por las autoridades universitarias para esta denegación era que, de hacerlo, la universidad estaría promocionando una determinada comprensión religiosa de la realidad, algo que expresamente veta la Establishment Clause de la Primera Enmienda. Pues bien, en este caso, la argumentación de la Corte Suprema giró en torno al concepto jurídico de designated public forum ${ }^{38}$. En precedentes anteriores, el Tribunal había diferenciado entre aquellas restricciones impuestas por el Estado en este tipo de foros y que toman en consideración el contenido material de los discursos excluidos, las cuales serían legítimas siempre y cuando tuvieran como finalidad no desnaturalizar el objeto de discusión sobre el que se quiera centrar el foro; $y$, en segundo lugar, las ya mencionadas view point discrimination, es decir, aquellas que no se basan en el contenido o el objeto material del discurso, sino en las propias valoraciones que se hacen sobre la materia que es objeto de debate en el foro. En definitiva, lo que nosotros entendemos como una discriminación por razón de pensamiento, opinión o ideología, y que, en armonía con la propia doctrina norteamericana sobre la libertad de expresión, estarían, en cualquier caso, prohibidas por la Primera Enmienda ${ }^{39}$. A partir de esta distinción, en Rosemberger $v$. Rector and Visitors, la mayoría del Tribunal entendió que las limitaciones impuestas a la participación de asociaciones

38 El fallo de la Corte en Rosemberger se apoya en dos precedentes, que, sin ser idénticos, tienen puntos en común con este litigio. En ambos casos se trataba de organizaciones religiosas que reclamaban las mismas condiciones de acceso que otros grupos a las instituciones públicas, en un caso a la universidad y en el otro a la escuela. En ambos casos, la Corte consideró que no se había podido demostrar la razonabilidad de la exclusión en el acceso a lo que calificó como non-public forum, y ello con el fundamento de que la Establisment Clause no impone un nivel de asepsia religiosa de las instituciones públicas, hasta el punto de excluir el acceso de todo punto de vista religioso, Widmar v. Vincent, 454 U.S. 263 (1981) Lamb's Chapel v. Center Moriches Union Free School District, 508 U.S. 384 (1993).

39 Para una crítica, partiendo de esta decisión, de la distinción entre viewpoint discrimination y content discrimination, basada en la falta de criterios en función de los cuales caracterizar a una discriminación como ideológica o de contenido, e insistiendo en cómo se tiende a considerar fuera de discusión ideológica posicionamientos que en sí mismos encarnan una ideología hegemónica, véase Kagan (1992: 70-71). 
religiosas en el programa público de promoción de las publicaciones universitarias constituía una discriminación no por razón de contenido —en tanto, en ningún caso, dicho programa excluía las publicaciones sobre religión de asociaciones laicas-, sino por razones estrictamente ideológicas; al ser únicamente la naturaleza confesional de la asociación la que servía de fundamento a la exclusión. No se trataba, por lo tanto, de un supuesto de government speech, sino de una regulación del discurso privado dentro de un foro público que, en tanto discriminatoria, vulneraba la libertad de expresión.

Para Alito, como decíamos, Rosemberger era el precedente adecuado en Walker v. Texas Division. En este sentido, su voto particular intenta, precisamente, llamar a la atención sobre la idea de que cuando el estado de Texas abrió la posibilidad de que los ciudadanos difundan determinados mensajes privados a través de un plataforma estatal, como las matrículas de los coches, dejó de hablar por sí mismo, y creó un limited public forum, en el que ya no está legitimado para establecer ningún tipo de restricción basada, como en este caso, en una valoración del significado del mensaje que se quiere trasmi$\operatorname{tir}^{40}$. En este sentido, Alito insiste en que el precedente de Summun no puede trasladarse aquí, en tanto, en aquel caso, se trataba de un espacio público por definición limitado, como es un parque, donde solo un número escaso de monumentos pueden ser exhibidos, mientras que en Walker v. Texas Division estamos ante una propiedad pública, las matrículas, a través de las cuales se pueden difundir tantos mensajes como propietarios de coches haya. En definitiva, las características del canal de comunicación que, en este caso, el estado de Texas ha abierto a los ciudadanos, obligan a considerar que, al contrario de lo que la mayoría del Tribunal había deducido, no se trata de un control del Estado sobre su propio discurso, sino sobre el que los ciudadanos exponen en un foro público creado desde las instituciones.

40 Con respecto a esto último, y para poner en evidencia que nos encontramos ante una discriminación por razones ideológicas, Alito establece un comparación entre el tratamiento que el Estado da a los proponentes de la bandera confederada con respecto a aquellos que propusieron, con éxito, la de los Buffalo Soldiers. La primera, sin duda, posee un significado supremacista y odioso para muchos ciudadanos norteamericanos, por más que también los hijos de los veteranos puedan ver en ella, simplemente, un símbolo que homenajea la memoria de sus padres. El problema es que esta misma naturaleza controvertida afecta también al símbolo que reconoce a los Buffalo Soldiers, el emblemático destacamento de afroamericanos que participó en la Guerra de Secesión, pero que también lo hizo en las despiadadas campañas contra los nativos en las Indian Wars; por lo que, entiende Alito, el razonamiento esgrimido para vetar la bandera confederada — que esta puede irritar a los afroamericanos — sirve también para cuestionar que sí se haya permitido el símbolo de los Buffalo Soldiers. 
Como insistiremos en el último epígrafe, la actitud reacia de la Corte a la hora de extender el concepto de public forum a otros ámbitos diversos a los tradicionales, patente en Walker v. Texas Division, tiene el efecto principal de incrementar paralelamente el ámbito de proyección de la doctrina del government speech, es decir, de extender el propio ámbito donde el discurso del estado se puede proyectar de forma hegemónica, sin necesidad de tolerar los discursos rivales. No debe olvidarse que son pocos los ámbitos que la Corte cataloga como foros públicos tradicionales. En este sentido, la decisión de considerar o no foros a nuevos ámbitos de dominio o propiedad estatal usados por los ciudadanos para comunicar sus ideas como foros públicos resulta determinante para valorar qué restricciones pueden imponerse allí sobre la libertad de expresión. Como habrá podido intuirse, la doctrina establecida en Walker v. Texas Division y Summun tiene el defecto de plantear una suerte de razonamiento circular, ya que la Corte afirma al mismo tiempo que el Estado no puede controlar el discurso privado dentro de un designated public form, pero que, en cualquier caso, si existe un control efectivo sobre los mensajes privados que acceden a su foro, no podrá considerarse que nos encontramos ante un foro público y, por lo tanto, las restricciones al discurso privado no tendrán que someterse a un estricto escrutinio judicial. En definitiva, el problema de esta doctrina es que, en buena medida, nos dice que para que el Estado pueda estar tranquilo acerca de la adecuación constitucional de las restricciones al discurso privado que haga en el ámbito de su competencia administrativa, lejos de velar por que estas sean mínimas y poco visibles, tiene que velar por lo contrario, de tal forma que se haga evidente que nos encontramos ante un foro bajo su dominio y, por lo tanto, en el que la Primera Enmienda no puede operar como límite.

\section{CUANDO EL DISCURSO PAGA UNOS DISCURSOS SÍ Y OTROS NO: EL «ESTADO PATRÓN» Y LA DOCTRINA DE LAS UNCONSTITUTIONAL CONDITIONS}

La teoría del government speech toma forma judicial a partir de un litigio, Rust v. Sullivan ${ }^{41}$, en el que la normativa cuestionada era un programa federal que ayudaba económicamente a las clínicas que ofrecían programas de asesoramiento y asistencia en materia de planificación familiar, pero que excluía del ámbito de potenciales beneficiarios a aquellos programas que contemplaban el aborto como un método más de planificación familiar. El argumento

41 Rust v. Sullivan, 500 U.S. 173 (1991). 
principal en virtud del cual se atacaba la normativa gira sobre la idea de que la misma no era una normativa neutral en relación a la cuestión del aborto, es decir, que se trataba de un programa que discriminaba a favor de un punto de vista moral concreto sobre la interrupción voluntaria del embarazo, castigando, de forma consecuente, a aquellas clínicas o profesionales que consideren que el aborto sí debe considerarse un método de planificación familiar.

Desde luego la decisión en Rust no puede ser leída al margen de la evolución que había experimentado, sobre todo a finales de los setenta y principios de los ochenta, la propia jurisprudencia de la Corte Suprema en materia de derechos sociales. Frente a las tentativas de dar cierta eficacia constitucional a obligaciones positivas por parte de los poderes públicos en materia de derechos, exploradas por la Corte en la década de los sesenta y setenta ${ }^{42}$, un tribunal con una nueva composición marcada por los cuatro jueces designados por Nixon $^{43}$, afirmó de forma rotunda el principio de que de la Constitución americana no puede deducirse ninguna obligación positiva —en el sentido de prestacional - con respecto a los derechos; de tal forma que toda política de promoción de cualquier libertad se considerará competencia exclusiva de las mayorías parlamentarias y no de los jueces ${ }^{44}$. En este sentido, incluso tomando en cuenta que desde la sentencia Roe $v$. Wade $e^{45}$ la decisión de la mujer de interrumpir voluntariamente el embarazo está amparada por una libertad constitucional, lo cierto es que hacer valer una dimensión prestacional de este derecho resultaba una tentativa difícil; de hecho, la Corte ya había consolidado el principio general de que «la decisión legislativa de no subsidiar el ejercicio de un derecho fundamental no puede equipararse a la vulneración del mismo» ${ }^{46}$. Del mismo modo, y en relación a las diferenciaciones normativas

42 Deduciendo derechos "positivos» de los ciudadanos a partir de la Equal Protection Clause, son conocidas las sentencias: Harper v. Virginia Board of Elections, 383 U. S. 663 (1966), Shapiro v. Thompson, 394 U. S. 618 (1969), King v. Smith, 392 U. S. 309 (1968). Sobre este ensayo exploratorio de la eficacia constitucional de ciertos derechos de prestación, puede verse, por todos, Michelman (1969).

Como es conocido, entre 1969 y 1972, el presidente Nixon nombró a los magistrados Warren Burger, Harry Blackmun, Lewis Powell y William Rehnquist.

44 La sentencia que certifica este cambio jurisprudencia es San Antonio Independent School District v. Rodriguez, 411 U. S. 1 (1973). Del debate doctrinal acerca de la eficacia judicial de los derechos sociales en Estados Unidos me he ocupado en un trabajo donde puede encontrarse una muestra de la bibliografía más relevante (Vázquez Alonso, 2014).

45 Roe $v$ Wade, 410 US 113 (1973).

46 Este principio tuvo su proyección en el ámbito que nos ocupa en Maher $v$. Roe, 432 U. S. 464 (1977), donde la Corte Suprema sostiene la constitucionalidad de excluir 
en la proyección de políticas sociales, el Tribunal también había tenido oportunidad de afirmar que «existe una diferencia básica entre la injerencia del Estado en una actividad protegida y la promoción (excluyente) de una actividad alternativa». Es decir, que ni la falta de desarrollo de la vertiente prestacional de un derecho ni la promoción pública de una actividad frente a su alternativa podían ser reconducidas, en virtud de los precedentes con los que contaba la Corte en Rust, a una infracción de la Constitución.

En cualquier caso, el litigio en Rust presentaba un elemento distintivo que no era sino la especial dimensión moral o ideológica que subyace tras la decisión de no extender las políticas de promoción de la planificación familiar a aquellos programas que contemplaran el aborto. Con esta decisión, sin duda, el gobierno prestaba su amparo explícito a una de las partes - la de las asociaciones provida - en la querella pública abierta sobre la cuestión del aborto, situándose, en este sentido, en una posición no imparcial o equidistante en relación a los distintos puntos de vista presentes en esta disyuntiva. La no neutralidad del programa aprobado por el gobierno era, a este respecto, indiscutible. La duda, por lo tanto, residía en si con esta discriminación a favor de una de las partes en conflicto el gobierno había sobrepasado los límites constitucionales que impone la Primera Enmienda a la restricción del discurso privado. La respuesta de la Corte Suprema no deja lugar a dudas. Para la mayoría del Tribunal:

El Gobierno puede, sin violar la Constitución, decidir financiar selectivamente un programa que busque promover ciertas actividades que él considera que son de interés público, sin al mismo tiempo financiar un programa alternativo que afronta el mismo problema desde otra perspectiva. Al hacer esto, el Gobierno no está discriminando por razones ideológicas; simplemente está eligiendo financiar una actividad con exclusión de otra.

Este párrafo, en el que la mayoría de los autores sitúan el origen del concepto jurídico de government speech, introduce una diferenciación

la práctica de abortos terapéuticos de la subvención pública cuando las mujeres que quieran que se les practique no puedan aportar un certificado médico al carecer de ingresos para poder costeárselo. En cualquier caso, la gran mayoría de los autores sitúan la consolidación definitiva de esta jurisprudencia en la opinión del juez Rehnquist, que será la de la mayoría del Tribunal, en Regan v. Taxation With Representation, 461 U.S. 540 (1983), en la cual se sostiene la adecuación constitucional de una ley federal que excluía a los asociaciones dedicadas a actividades «lobbistas» dirigidas a influir en las asambleas legislativas de las entidades sin ánimo de lucro que se beneficiaban de una política de incentivos fiscales a las donaciones privadas. 
determinante para interpretar los límites del Estado a la hora de financiar el discurso privado. Así, si bien cuando el Estado decide implementar políticas públicas que promuevan la libertad de expresión no puede imponer ningún tipo de restricciones en el ámbito de los beneficiarios por motivos ideológi$\cos ^{47}$, nada en la Constitución impide al legislador fijarse ciertos objetivos sobre la base de sus propias orientaciones políticas, y promocionarlos de forma excluyente a sus alternativas. Como subraya la mayoría de la Corte en Rust, al determinar que solo aquellos programas que no contemplen el aborto como método de planificación familiar son susceptibles de recibir financiación federal, el legislador estaría únicamente fijando cuál es el objetivo de su política pública y no estableciendo lo que, según la conocida doctrina elaborada por la Corte Suprema, supondría una "condición inconstitucional» ${ }^{48}$, es decir, el ofrecimiento condicionado de un beneficio público a cambio de que los receptores se rindan en el ejercicio legítimo de una libertad constitucional, en este caso, la libertad de expresión (Sullivan, 1991).

El elemento clave en el razonamiento de la Corte se encuentra, por lo tanto, en que la condición establecida por el legislador no restringe realmente la libertad de expresión, en tanto no obliga a los receptores a rendirse a favor de un determinado discurso ideológico contrario al aborto, y es coherente, a su vez, con el objetivo que persigue el plan de financiación federal, o, podríamos decir nosotros, es expresión del discurso que — legítimamente- quiere hacer valer un determinado gobierno. Un razonamiento, este último, en el que creo que subyace el presupuesto, por otro lado lógico, que, de que si bien el gobierno puede permitirlo todo, no puede financiarlo todo, de tal forma que, necesariamente, va a existir una desigualdad en la afectación del gasto público a determinados fines. La incidencia que esta afectación pueda tener sobre la libertad de expresión no planteará ningún problema de constitucionalidad siempre y cuando pueda demostrarse que dicha afectación no es en sí misma coercitiva y que, en cualquier caso, es coherente con la propia finalidad del programa.

La jurisprudencia posterior de la Corte Suprema contiene ejemplos de cuáles serían los límites a la doctrina Rust en ciertos ámbitos donde la libertad

47 Rehnquist, "Congress may not discriminate insidiously in its subsidies in such a way as to aim at the suppression of dangerous ideas", Regan $v$. Taxation with Representation, 461 U.S. 540, 548 (1983).

48 Como es sabido, quien acuña el término e introduce en el debate doctrinal la necesidad de equiparar el tratamiento jurídico de la compulsión estatal para la renuncia al ejercicio de determinados derechos a las prohibiciones es Rort L. Hale, con su artículo Unconstitutional Conditions and Constitutional Rights, publicado en la década de los treinta en la Columbia Law Review (Hale, 1935). 
de expresión y comunicación adquieren un valor específico. A este respecto, si bien en Rust la mayoría del Tribunal entendió que la discriminación a favor de los programas de planificación familiar que no contemplaban el aborto como método no afectaba a la necesaria libertad que ha de existir en la relación de diálogo entre médico paciente ${ }^{49}$, años después, en Legal Services Corporation $v$. Velazquez $^{50}$, la Corte Suprema declaró la inconstitucionalidad de un programa federal que destinaba sus fondos a un organismo público creado para dar asistencia letrada a personas sin recursos. En este caso, el condicionante establecido por el legislador era que, en ningún caso, dichos fondos se usaran en litigios donde se pusiese en cuestión cualquier norma que consagrara una política pública del Estado. Para la mayoría del Tribunal, a diferencia de Rust, no podía hablarse, en esta ocasión, de un supuesto de government speech, y ello porque el programa, en puridad, afectaba a un ámbito laboral donde el discurso es estrictamente privado - el de las relaciones entre el abogado y su cliente- sin que pueda, por lo tanto, considerarse una manifestación del discurso político que quiera implementar y promocionar una determinada administración. Era, en definitiva, una condición inconstitucional que buscaba disuadir a los abogados de algo tan elemental en el oficio como es el poder cuestionar la licitud de una norma aplicable.

A la misma conclusión llega el Tribunal en un litigio muy similar a Rust Agency for International Development v. Alliance for Open Society International, $I n c$, donde la normativa en cuestión versaba en un programa de ayuda financiera a las organizaciones no gubernamentales que dedican sus esfuerzos a lucha contra el sida. Las condiciones impuestas para los receptores de estas ayudas eran dos: por un lado, los fondos no podían tener como destinatarios a asociaciones que promuevan la legalización o la práctica de la prostitución; $y$, en segundo lugar, tampoco podrían favorecer a aquellas organizaciones que no tuvieran una política explícita de condena de la prostitución, hasta el punto que el propio programa exigía a las entidades receptoras que firmaran un documento preestablecido en el que se condenaba esta práctica. Como puede intuirse, aquí el conflicto se producía de nuevo entre la idea que encarna el

49 Y ello, con el argumento de que el silencio de los doctores, a la hora de ofrecer este remedio, no tenía que interpretarse por los pacientes como un rechazo personal al mismo, sino simplemente como una consecuencia lógica de que tal terapia se situaba al margen de la finalidad del programa. Frente a esta conclusión de la mayoría, llamando la atención sobre el hecho de que esta regulación de la relación médico paciente, tiene el propósito y el efecto de manipular la decisión de aquellas pacientes que no quisieran continuar con su embarazo, véase el voto particular de Blackmun Rust v. Sullivan, 500 U.S. 173 (1991) 204 (Blackmun, J., dissenting). 
concepto de government speech — que el gobierno puede legítimamente hacer efectivo un discurso político propio, en este caso, contra la prostitución-y aquella otra que se encuentra en el corazón de la Primera Enmienda, y que es la de que la Constitución prohibits the government from telling people what they must say. Lo cierto es que en muy distintos ámbitos de la jurisprudencia norteamericana, desde el federalismo fiscal ${ }^{51}$ hasta la libertad religiosa ${ }^{52}$, la idea de coerción ha servido a la Corte Suprema como elemento decisivo en no pocos casos difíciles. Identificar la línea que separa el incentivo de la coacción no es una cuestión sencilla, de hecho, la propia Corte había sido reacia a censurar aquellos programas que más que coaccionar provocaban un cierto efecto desalentador sobre el ejercicio de algunas libertades ${ }^{53}$, sin embargo, en este caso, hay un elemento que resulta determinante para que la mayoría de la Corte entienda que el gobierno federal la había sobrepasado y este es el hecho de que

51 En este sentido, la distinción entre la legítima persuasión financiera de la federación a los estados para que estos participen de sus programas de gasto, y la coacción federal a los estados prohibida por la Constitución, sigue siendo una cuestión clave en la interpretación de la Necessary and Proper Clause y la Commerce Clause, tal y como recientemente ha puesto de manifiesto la sentencia sobre la reforma sanitaria emprendida por Obama: National Federation of Independent Business v. Sibelius, 567 U.S. 59 (2012). Sobre esta cuestión me he ocupado en extenso en Vázquez Alonso (2014).

52 En este sentido, es conocido el precedente de Lee v. Weisman, 505 U.S. 577 (1992), donde el juez Kennedy, ponente de la sentencia, aboga por sustituir el denominando Lemon Test, en aplicación de la Establisment Clause, por un Coercion Test, donde el nivel de neutralidad exigido se determine por la ausencia de coacción.

53 Como exponente de esta problemática se suele aludir a la libertad artística, y, en concreto, al litigio National Endowment for the Arts v. Finley, 524 U.S. 569 (1998), donde la Corte Suprema entendió que era conforme a la Primera Enmienda someter a un canon no solo de excelencia sino también de decencia a los trabajos artísticos que podían beneficiarse del principal programa federal para el fomento de las artes. Una jurisprudencia que en su día fue criticada desde el presupuesto de que la promoción parcial de la libertad artística, supeditada a un canon de moralidad, podría tener como consecuencia - considerando la incidencia creciente que tiene la presencia del Estado como patrón en este ámbito- la desnaturalización de una libertad que no puede ser concebida sin su elemento irreverente o libérrimo, y que, por lo tanto, excluye, no solo cualquier tipo de censura estatal, sino también cualquier tipo de política pública que quiera arrinconar una determinada visión artística de la realidad. Para una crítica de la reforma de la legislación federal, luego derogada, que introducía el canon de decencia, puede verse Fiss (1991), Sullivan (1991: en especial, 91-95). Sobre la propia sentencia, y con carácter general, sobre el problema de la subvención estatal a la libertad artística, es referencia inexcusable Bezanson (2013: en especial 7-50). 
la normativa no permita a las asociaciones guardar silencio acerca de lo que cada una de estas opinen sobre el ejercicio de la prostitución ${ }^{54}$.

Como ya habíamos visto en los supuestos de open forum, el factor clave en el análisis de la Corte en realidad se encuentra en determinar si la normativa regula y es expresión del discurso gubernamental, o bien si se trata de la regulación de un discurso privado; de tal forma que si constatamos que nos encontramos en el primer supuesto, las desviaciones en el tratamiento igual de los distintos puntos de vista ideológicos carecerán de relevancia en el juicio de constitucionalidad, mientras que en el segundo caso serán determinantes ${ }^{55}$. En este sentido, en la doctrina judicial sobre el subsidized speech, como ya presagiara Robert Post, lo relevante no ha sido tanto el discurso privado sobre el que se proyecta el subsidio — qué libertad ha sido asistida por el Estado-, sino si la normativa es expresión coherente de una política pública del Estado dentro de un ámbito administrativo de su competencia. Dicho de otra forma, si se trata o no de ese foro exclusivo y judicialmente impune en el que se expresa el government speech. Si nos encontramos dentro de este foro, las desigualdades en la proyección de ciertas ayudas públicas hemos de entenderlas como una suerte de decision rules dentro del ámbito administrativo, y su relación con los límites que establece la Primera Enmienda nada tiene que ver con

54 Como podemos apreciar, para el Tribunal, la gran diferencia entre Rust y Alianza for Open Society reside en que, en el primer caso, la norma no exigía ninguna condena explícita del aborto por parte de las entidades participantes en el programa, sino simplemente que estas se abstuvieran de ofrecer ese remedio en el ámbito concreto de la aplicación del programa para así no perturbar el objetivo concreto de la política estatal. En Alianza, por el contrario, la normativa exige un explícito posicionamiento moral contrario a esta práctica, un elemento que, para la mayoría del Tribunal, resulta clave a la hora de considerar que los condicionantes que introduce la normativa no están vinculados a los objetivos gubernamentales que persigue el programa y, por lo tanto, al amparo del concepto jurídico de government speech, sino que se proyectan, de forma indirectamente coercitiva, pero coercitiva en cualquier caso, sobre el discurso privado, imponiendo un límite a la libertad de expresión de los participantes basado en motivos estrictamente ideológicos y, por lo tanto, contrario a la Primera Enmienda de la Constitución.

$55 \mathrm{Y}$ es que cuando el gobierno regula el discurso privado no solo no cabe establecer ningún tipo de discriminación por motivos ideológicos (view point discrimination), sino que, de hecho, la jurisprudencia de la Corte Suprema en ocasiones también ha sometido a un estricto escrutinio aquellas regulaciones del discurso privado que restringen la libertad de expresión no ya mediante la censura ideológica sino a través de una meramente temática (subject matter restrictions), tomando en consideración que, limitando la posibilidad de tratar ciertos temas, en el fondo, en muchos casos, lo que se está prohibiendo es la expresión de concretos puntos de vista (Sullivan, 1991: 88-89). 
lo que serían las conduct rules, a través de las cuales el Estado no quiere regular ámbitos de su administración para definir sus políticas, sino el comportamiento de los ciudadanos ${ }^{56}$.

\section{CUANDO (TODOS) PAGAMOS EL DISCURSO QUE EL GOBIERNO QUIERE}

Que no hay cosa cierta salvo la muerte y los impuestos no es únicamente una frase ingeniosa de Benjamin Franklin ${ }^{57}$, sino también un principio no escrito de la Constitución americana que tiene no pocas consecuencias prácticas a la hora de valorar la adecuación constitucional de ciertas políticas públicas $^{58}$. La importancia normativa de esta idea tiene, en cualquier caso, una doble dimensión, ya que no solo nos dice algo tan básico como que el Estado legítimamente puede gravar la renta y la riqueza de los ciudadanos ${ }^{59}$, sino también que puede gravarla con determinados fines, es decir, para financiar concretas políticas públicas. En este sentido, el poder impositivo del Estado está directamente relacionado con la propia idea de government speech: el Estado habla a través de sus políticas públicas y el rastro del gasto público traza también un relato ideológico que, lejos de ser neutral, es indicativo de ciertas preferencias que, en último término, serán juzgadas dentro del proceso político, y atacadas por grupos de presión, pero no por los jueces. La Primera Enmienda no consagra, por lo tanto, ningún derecho a favor de los ciudadanos para resistirse a participar con el producto de su renta o de su riqueza en aquellas políticas públicas que, siendo expresión legítima del discurso del gobierno, contradicen sus propias ideas personales sobre lo bueno

56 Robert Post sigue aquí la terminología acuñada en el ámbito del derecho penal por Dan-Cohen (1984).

57 Letter from Benjamin Franklin to M. Le Roy (nov., 1789) «Our new Constitution is now established ... but in this world nothing can be said to be certain, except death and taxes».

58 Como último ejemplo, cabe recordar que el poder estatal para gravar la renta ha servido a la Corte para avalar el controvertido indiviudal mandate de adquirir un seguro sanitario que impuso la reforma sanitaria de 2010, National Federation of Independent Business v. Sibelius, 567 U.S. (2012).

59 La Taxing and Spending Clause viene consagrada en el art. 1, sec. 8, cl. 1. a de la Constitución: «The Congress shall have Power To lay and collect Taxes, Duties, Imposts and Excises, to pay the Debts and provide for the common Defence and general Welfare of the United States; but all Duties, Imposts and Excises shall be uniform throughout the United States». 
y lo justo ${ }^{60}$. Como bien se deduce de la sentencia de Franklin, los impuestos son lo que son, y este conflicto entre conciencia personal y destino del gasto público es un conflicto que no tiene otra solución para el ciudadano que la de apoyar democráticamente aquella oferta política que más se adecua a su forma de entender lo correcto, lo que, en ningún caso, derogará el principio de que el Estado puede determinar sus fines, y que este poder, irremediablemente, redefine ciertos derechos naturales, tal como ya explicara Jay en este conocido párrafo de El Federalista:

Nada es más cierto que la indispensable necesidad de gobierno, y es igualmente innegable que desde el momento en el que este se constituye, el pueblo debe ceder al gobierno establecido algunos de sus derechos naturales para que éste pueda disponer de los poderes requeridos para el ejercicio de sus funciones ${ }^{61}$.

Pese a que el punto de partida teórico, la legitimidad del gobierno para imponer tributos con los que financiar su discurso puede parecer inequívoca, la realidad constitucional ha puesto de manifiesto que también en este ámbito vamos a encontrar casos difíciles, donde no esté del todo claro si el discurso que el ciudadano se ve obligado a financiar es realmente el discurso del gobierno o un discurso privado contrario a sus principios. Uno de ellos, y tal vez el que más críticas ha despertado en relación a la doctrina judicial del government speech, es el que juzga la Corte en Johanns v. Livestock Marketing ${ }^{62}$. Los antecedentes de hecho de este litigio son los siguientes. En 1986 el Congreso federal aprobó un plan para promover el consumo de carne nacional. En el marco de la ejecución de este programa, la Secretaría de Estado de Agricultura puso en funcionamiento una mesa de representación de las distintas industrias ganaderas, y dentro de esta, un órgano de dirección integrado también por ganaderos, que, entre otras competencias, tenía la de diseñar campañas institucionales de marketing a favor del consumo de carne nacional. Unas campañas que se financiarán a través de un impuesto que grava con un dólar por cabeza de ganado la venta y exportación de estas reses vacunas por parte de todos los ganaderos que participan como beneficiarios del programa federal. La campaña que da origen a este litigio estaba basada en el lema Beef. It's What's for Dinner que lucía en distintos carteles anunciadores en los que

60 «It cannot be that all taxpayers have a First Amendment objection to taxpayer-funded government speech, even if the funded speech is not 'germane' to some broader regulatory program», Johanns v. Livestock Marketing 544 U.S. 550 (2005).

61 The Federalist Papers (2003: 7-8). La traducción es mía.

62 Johanns v. Livestock Marketing 544 U.S. 550 (2005). 
también podía leerse en su parte inferior la rúbrica: Funded by America's Beef Producers. Algunos ganaderos que formaban parte de la Mesa del Ganado, y que por tanto se habían visto obligados a sufragar con el impuesto de un dólar por res la campaña publicitaria, cuestionaron la constitucionalidad de esta imposición al considerar que se trataba de un impuesto que, en último término, vulneraba su libertad de expresión, al imponerles de forma coercitiva financiar un discurso con el que no estaban de acuerdo.

La doctrina constitucional sobre la financiación forzada del discurso ajeno, la denominada compelled subsidization of speech doctrine, había sido definida por la Corte con unos perfiles relativamente claros ${ }^{63}$. Así, del mismo modo que el Estado no puede exigir que los ciudadanos hagan suyo un discurso que no comparten, la jurisprudencia había insistido en que la Primera Enmienda también exige que sea sometida a un estricto escrutinio cualquier norma que obligue a los ciudadanos a financiar un discurso con el que no están de acuerdo ${ }^{64}$. De hecho, en una decisión relativamente cercana a United States v. United Foods, Inc. ${ }^{65}$, la Corte Suprema consideró contrario a la libertad de expresión el impuesto establecido a los productores de champiñones para financiar campañas publicitarias que incitaran al consumo de este producto. Sin embargo, en Johanns v. Livestock la conclusión de la mayoría de jueces va a ser la contraria. El elemento diferenciador, en este caso, será que, en último término, quien crea el organismo encargado de la promoción del producto, y quien da el visto bueno al mensaje publicitario que se elige, es el gobierno federal a través del Congreso y de la Secretaría de Estado de Agricultura, con lo cual nos encontramos ante un caso de government speech ${ }^{66}$. Este dato cambia radicalmente, para la Corte

63 Sobre esta doctrina y su proyección en el concreto ámbito de la publicidad, véase Post (2005).

64 Véanse Abood v. Detroit Bd. of Ed., 431 U. S. 209 (1977); Keller v. State Bar of Cal., 496 U.S. 1 (1990). Detrás de esta jurisprudencia se encuentra una vieja idea de Jefferson, plasmada en su alegato a favor de la libertad expresión «to compel a man to furnish contributions of money for the propagation of opinions which he disbelieves, is sinful and tyrannical». 5 The Founders' Constitution, \$37, A Bill for Establishing Religious Freedom, p. 77 (1987). Citado en (Souter dissenting) Johanns v. Livestock Marketing 544 U.S. 550 (2005).

65 United States v. United Foods, Inc., 533 U.S. 405 (2001). Una sentencia que en buena medida rectificaba otro precedente reciente, el establecido en Glickman v. Wileman Bros. \& Elliott, 521 U.S. 457 (1997), donde, en este caso, la Corte Suprema había considerado que no era contrario a la Primera Enmienda un programa estatal que exigía la contribución de los productores de fruta de California a una campaña publicitaria de estos productos.

66 Johanns v. Livestock Marketing 544 U.S. 550, 563-64 (2005). 
Suprema, el parámetro de análisis, no siendo aplicable, como había entendido el tribunal de circuito, la doctrina general sobre compelled speech elaborada a través de litigios donde el discurso que se obligaba a financiar al ciudadano era un discurso privado, sino la doctrina general sobre el government speech, en virtud de la cual, como hemos visto, el gobierno no está constreñido por la Primera Enmienda a la hora de implementar su discurso político ${ }^{67}$. Lo significativo de la decisión es que a esta doctrina permisiva la Corte añade un nuevo supuesto, al reconocer que el Gobierno puede financiar su propio discurso con la contribución de los ciudadanos disidentes ${ }^{68}$ incluso a través de impuestos de carácter sectorial $^{69}$, y para difundir mensajes que, pese a estar bajo su supervisión final, son en gran medida elaborados por concretos grupos de interés que han podido encontrar un encaje institucional hegemónico.

Como sugiere el voto particular que redacta Souter, el dato más significativo de Johanns v. Livestock, y al mismo tiempo, el exponente más claro de los riesgos que comporta la expansión de una categoría jurídica como la de government speech, que inmuniza un ámbito de la actividad gubernamental frente a las demandas de protección de la libertad de expresión, es la dificultad que existe en algunos casos para que los ciudadanos puedan realmente identificar al Estado detrás de un determinado mensaje. Como hemos visto, en este caso, los carteles publicitarios que fueron objeto de litigio se rubricaban con la firma America's Beef Producers, tras la cual es probable que la mayoría de los ciudadanos vieran, no al gobierno federal, sino a concretos grupos de interés ${ }^{70}$.

67 Entre otros, especialmente crítico con lo que para él constituye un cambio de doctrina en la regulación del discurso comercial subsidiado, excesivamente restrictivo de la libertad de expresión, véase Troy (2005: 125-126).

68 Insistiendo en que «it seems inevitable that funds raised by the government will be spent for speech and other expression to advocate and defend its own policies», véase (Thomas y Scalia, concurring) Johanns v. Livestock Marketing 544 U.S. 550 (2005).

69 Sobre la improcedencia de equiparar el tratamiento jurídico de la financiación del discurso gubernamental a través de impuestos generales de aquellos otros supuestos donde el vínculo entre el impuesto y el discurso estatal es mucho más nítido al tratarse de ámbitos sectoriales, insistió Souter, en su voto particular: «the relative palatability of a remote subsidy shared by every taxpayer is not to be found when the speech is funded with targeted taxes. For then, as here, the particular interests of those singled out to pay the tax are closely linked with the expression, and taxpayers who disagree with it suffer a more acute limitation on their presumptive autonomy as speakers to decide what to say and what to pay for others to say», (Souter, dissenting) Johanns $v$. Livestock Marketing 544 U.S. 550 (2005).

70 "...the Beef Act does not establish an advertising scheme subject to effective democratic checks. ... the ads are not required to show any sign of being speech by the 
El problema, por lo tanto, reside en que si bien el punto de partida de la doctrina del government speech se encuentra en la idea de que la responsabilidad del gobierno por su discurso ha de ser una responsabilidad política y no judicial, la dificultad para identificar a la institución que promueve un determinado mensaje puede situar a los poderes públicos en una posición de total inmunidad de control, ya que ni es posible controlar judicialmente las desviaciones del tratamiento neutral de las distintas opiniones de los ciudadanos, ni tampoco someter a un verdadero control político las mismas, y ello debido a que, en muchos casos, los ciudadanos ni siquiera van a saber que el gobierno es quien se encuentra tras la promoción de ciertos mensajes ${ }^{71}$. En Johanns $v$. Livestock, por lo tanto, se constata la inexistencia de mecanismos judiciales de análisis que sirvan para contrastar la presencia de lo que podríamos llamar un «discurso gubernamental putativo», en donde la paternidad gubernamental solo aparece cuando es necesario apelar a ella para eximir de responsabilidad al gobierno - en virtud de la doctrina del government speech — por las desviaciones en el tratamiento constitucionalmente exigido de la libertad de expresión de los ciudadanos.

\section{A MODO DE CONCLUSIÓN: RECAPITULACIÓN CRÍTICA A UN CONCEPTO JURÍDICO RAZONABLE}

Una de las características de la jurisdicción de la Corte Suprema norteamericana ha sido su capacidad para, en diálogo con la doctrina académica, idear conceptos constitucionales que integren y adapten el texto constitucional, ofreciendo respuesta a cuestiones no previstas por el constituyente pero que la propia evolución experimentada desde principios del siglo XX en la comprensión del Estado y de la misma sociedad ha ido demandando. Sin duda, la doctrina government speech es un exponente de este virtuosismo creativo que, en este caso, quiere ofrecer un marco teórico que dé solución a la pregunta de qué umbral de neutralidad impone una Constitución liberal a un Estado que asume un papel activo en diversos ámbitos de la sociedad, poniendo

Government, and experience under the Act demonstrates how effectively the Government has masked its role in producing the ads», (Souter, dissenting) Johanns v. Livestock Marketing 544 U.S. 550 (2005).

71 «Expression that is not ostensibly governmental, which government is not required to embrace as publicly as it speaks, cannot constitute government speech sufficient to justify enforcement of a targeted subsidy to broadcast it», (Souter, dissenting) Johanns v. Livestock Marketing 544 U.S. 550 (2005). 
en práctica un discurso político que varía en función de la ideología política que salió victoriosa de los distintos procesos democráticos. El concepto de government speech parte, en este sentido, de un presupuesto lógico difícil de negar: todo gobierno democrático desarrolla un discurso ideologizado, no neutral frente a las diferentes concepciones políticas existentes en la sociedad, y su control, en un Estado democrático, corresponde al proceso político y no a los jueces. Se trata por ello de una doctrina judicial conceptualmente sólida, pero esa misma solidez, como hemos visto, es también causa de una visible tendencia expansiva que obliga a repensar sus límites internos en sentido crítico. Si hasta ahora el análisis que hemos hecho de esta categoría ha sido un análisis, podríamos decir, intrasistémico, en tanto toma en consideración única y exclusivamente el desarrollo jurisprudencial y la doctrina norteamericana, en la crítica que avanzaremos a continuación incluiremos también algunas reflexiones sobre esta cuestión desde la perspectiva de un ordenamiento jurídico como el español, representativo de un constitucionalismo donde la acción de gobierno no solo está vinculada a las claves ideológicas de los partidos mayoritarios, sino también, y a diferencia de un modelo como el norteamericano, a los propios principios programáticos consagrados en el texto de la Constitución (Porras Nadales, 2014: 71-78). En este sentido, si bien los problemas que plantea la idea de government speech son similares, y la propia categoría es inteligible y útil desde la perspectiva de nuestra cultura constitucional, sus implicaciones no son idénticas.

Como hemos podido ver en el último de los epígrafes, la principal crítica que se hace a la doctrina del government speech está relacionada con la inexistencia, dentro del esquema de análisis de la Corte, de un requisito de control que contraste la transparencia en el discurso gubernamental, concretamente, la transparencia acerca de la autoría del discurso. La exigencia de hacer explícita la autoría estatal del discurso que subyace tras una política pública no solo tiene la finalidad democrática de vedar cualquier posibilidad de que el Estado use a los ciudadanos como subterfugio para eximirse de responsabilidad política por su gestión, sino también la de proteger la propia libertad de elección de estos frente a un mensaje que el gobierno puede distorsionar si lo propaga por medio de diferentes máscaras ${ }^{72}$. Tras la exigencia de transparencia, por lo

72 En Rust v. Sullivan, como se ha visto, la Corte considera que condicionar la subvención a clínicas de planificación familiar a que no hagan ninguna referencia al aborto como instrumento de planificación es algo que puede hacer el Congreso federal, en tanto no es sino exponente de su propio discurso político en materia de natalidad. Partiendo de esta premisa, podemos situarnos en el supuesto concreto en que una mujer acuda a una de estas clínicas y al requerir a su doctor información sobre la posibilidad de 
tanto, no hay solo una preocupación por los valores democráticos, sino también por el ejercicio de los derechos, aunque en ambos casos la finalidad de aclarar al ciudadano los pormenores de la actuación pública sea la misma: la posibilidad de control y de imputación. Como se ha señalado recientemente, la transparencia con respecto a la autoría mediata de las políticas no es, en realidad, sino una suerte de imposición de la virtud del coraje en el discurso gubernamental en cualquier ámbito y sea cual sea el grado de la intervención estatal (Norton, 2015: 61), sin que con ello se debilite el principio fundamental que subyace tras la idea jurídica de government speech, que es la de que el gobierno no ha de ser neutral ideológicamente, y que solo el proceso político democrático, entendido este en sentido amplio, puede controlar las desviaciones ideológicas de su proyecto con respecto al sentir mayoritario de la sociedad o de ciertos ámbitos de esta. Por todo ello, la transparencia en la autoría en realidad tiene que entenderse como el eslabón lógico para conectar en la práctica los conceptos de government speech y responsabilidad política. En este sentido, la necesidad de controlar al gobierno «ventrílocuo», que actúa a través de máscaras, adquiere sin duda mayor relevancia ante la progresiva falta de nitidez de la línea que marca la tradicional distinción entre sociedad y Estado, con la correspondiente asunción de funciones públicas por parte de agentes privados, sobre las cuales el Estado mantiene aún un importante grado de control y por lo tanto de responsabilidad (Esteve Pardo, 2013).

A este respecto, y más allá de las propuestas lege ferenda para profundizar en la transparencia de las labores de gobierno, una parte importante de la doctrina norteamericana ha secundado la propuesta que el juez Souter realiza en su voto particular a Summun, de integrar en los casos de government speech, el concepto de «observador razonable» que en su día la juez O’Connor

abortar este guarde silencio sobre esta opción, tal y como impone el programa federal, $\mathrm{y}$, sin embargo, ponga en conocimiento de la paciente otras fórmulas alternativas. Ante esto, la reacción lógica de la paciente será pensar que la interrupción del embarazo no es una opción deseable para el médico que la está atendiendo, cuando, en realidad, quien censura esa opción no es necesariamente el médico sino el estado. Del mismo modo, la mujer que considere intolerable que en un clínica de planificación familiar, financiada con fondos públicos, no se haga referencia a la posibilidad de interrumpir su embarazo, cuando esta acción está amparada por una libertad constitucional, censurará, en primera instancia, la actitud del médico o de la clínica privada en la que la han atendido, pero no la del Estado. Desde luego, todo esto cambiaría si a cada paciente que acude a una clínica que se acoge al programa federal de incentivos se le deja claro que el aborto no se contempla como un método de planificación familiar porque así se exige en la legislación federal, como condición para poder participar en un programa de estímulo financiero. 
desarrollara en el ámbito de la Establishment Clause. La idea, en este sentido, es que en los supuestos en los que el gobierno apele a la doctrina del government speech para eximirse de responsabilidad jurídica, el juez adopte en su juicio una perspectiva imparcial entre el Estado y el ciudadano demandante, que sería la de alguien bien informado sobre el contexto particular en el que el Estado actúa, todo ello para determinar si en realidad es fácilmente reconocible la autoría estatal sobre el discurso, o si, por el contrario, la intuición natural de los receptores va a ser imputar la autoría y, por lo tanto, la responsabilidad, a aquellos ciudadanos o instituciones a los cuales el "Estado ventrículo» usa como máscaras difusoras de su mensaje (DeNigris, 2010: $60)^{73}$. En este segundo caso, la doctrina del government speech, es decir, el principio de que «cuando el gobierno habla, para promocionar sus propias políticas o sus ideas particulares, en último término sólo es responsable democráticamente», sería desplazado, a favor de un pleno control judicial de los actos de gobierno, en el que sería censurable la parcialidad ideológica de sus políticas.

Más allá de las evidencias lógicas que ponen de manifiesto su valor democrático, la insistencia doctrinal sobre la necesidad de imponer un mínimo de transparencia en el discurso gubernamental como presupuesto para la aplicación de la doctrina del government speech tiene mucho que ver con las nuevas posibilidades que ofrece la red a las distintas administraciones, no solo para visibilizar la acción de gobierno, sino también, desde la irrupción de internet 2.0, para interactuar con los ciudadanos, abriendo los canales institucionales de comunicación digital a su participación. Desde luego, la dificultad para conciliar la denominada "gobermedia» con la exigencia de un mínimo de neutralidad estatal en sus espacios virtuales tendría que ser objeto de un análisis que desborda el propósito de este trabajo, no obstante, tomando en consideración la doctrina constitucional del government speech y la idea de transparencia, la cuestión principal que surge, y que sin duda no es ajena a nuestro ordenamiento, no es tanto la de cómo identificar cuándo una determinada página es una plataforma del discurso público, algo que se logra con la exclusividad en el uso de ciertos dominios y direcciones URL, sino, sobre todo, la

73 Desde luego, al concepto de reasonable observer se le pueden aplicar en este ámbito las mismas críticas que la doctrina americana le dedica en el ámbito de la Establishment Clause, y que tienen que ver con la dificultad determinar judicialmente cuál es la perspectiva judicial imparcial y correcta desde la que mirar. En cualquier caso, y más allá de su dificultad, parece evidente la necesidad de integrar una suerte de test sobre la transparencia en la aplicación de la doctrina del government speech para garantizar, no que el gobierno sea neutral, sino que sus parcialidades le sean imputables y, en su caso, que no queden impunes frente al proceso político. 
de hasta qué punto una web gubernamental, abierta a la participación ciudadana, puede discriminar entre links y comentarios, suprimiendo aquellos que considere contrarios al mensaje que quiere transmitir (Ardia, 2010: 20312036). Como puede intuirse, la cuestión aquí radica en hasta qué punto puede o no considerarse una web gubernamental, abierta a la interacción de los ciudadanos, un public forum o un designated public forum, donde, como vimos anteriormente, cualquier limitación al discurso privado estará sometida a un estricto escrutinio. A día de hoy la Corte Suprema norteamericana no se ha pronunciado sobre la naturaleza jurídica de estos foros, pero hasta cuatro tribunales de circuito $^{74}$ y la propia Corte Suprema de California ${ }^{75}$ han reiterado que las páginas web 2.0 de las instituciones públicas deben considerarse un exponente de government speech, y que no pueden ser subsumibles dentro del concepto de designated public forum al existir un control final del gobierno sobre ellas; con lo cual, el Estado puede censurar el discurso privado que en ellas se desarrolle sin estar limitado por la Primera Enmienda de la Constitución o, dicho de otra forma, sin mostrarse neutral o equidistante ante los distintos puntos de vista que allí se exponen. La Corte Suprema tendrá pronto la oportunidad de confirmar o no esta interpretación restrictiva de libertad de expresión en el foro estatal virtual, de hacerlo sin más matices, no estaría sino confirmando una interpretación marcadamente propagandística y también iliberal de las plataformas virtuales estatales. Lo cierto, en este sentido, es que, como hemos podido ver en el epígrafe dedicado al concepto constitucional de foro público, más allá de los foros públicos tradicionales, los jueces del Tribunal Supremo no han sido especialmente proclives a reconocer nuevos ámbitos asimilables, siempre que exista un cierto control del Estado sobre los discursos que en ellos se manifiestan.

Al margen de la crítica a la que ya hicimos alusión, que es la de su carácter circular y paradójico - es un foro público aquel en el que el Estado no desempeña un control, pero si el Estado tiene control sobre el mensaje final ya no lo es-, esta doctrina plantea el problema de que, al centrar el punto de vista en cómo el Estado considera un determinado foro - suyo o público- y no en cómo los ciudadanos lo ven, permite a los jueces eximirse de proteger la

74 Sutliffe v. Epping Sch. Dist., 584 F.3d 314, 333-34 (1st Cir. 2009); Hogan v. Twp. of Haddon; 278 F. App'x 98, 102 (3d Cir. 2008); Page v. Lexington, Cnty. Sch. Dist. One, 531 F.3d 275, 285 (4th Cir. 2008); Putnam Pit v. City of Cookville, 221 F.3d 834, 84445 (6th Cir. 2000) Sobre esta jurisprudencia, véase Xiang Lee (2013: 316-318).

75 Vargas v. City of Salinas, 205 P.3d 207, 215 n.8 (Cal. 2009). De una manera más general, sobre la consideración que hace la jurisprudencia estadounidense en torno a la red, en sí, como medio de comunicación pública, Rodríguez-Izquierdo Serrano (2013: 110-115). 
libertad de expresión en ámbitos que, independientemente de su carácter público, pueden constituir para los ciudadanos plataformas fundamentales para expresar libremente sus propias ideas. En el ordenamiento español no hay una regulación general que establezca en qué se concreta la neutralidad de las administraciones públicas en la red, siendo las diferentes guías de actuación que en los distintos niveles de gobierno se han aprobado los únicos criterios establecidos para actuar en aquellos supuestos donde la interacción de los ciudadanos en las plataformas institucionales pueda plantear ciertos problemas. En cualquier caso, como ha sido señalado por la doctrina, lejos de asumir la idea de que en estas plataformas existe una libertad de filtrado por parte de las administraciones, y tomando en consideración el marco constitucional de la libertad ideológica, parece claro que cualquier censura de comentarios o intervenciones de los ciudadanos que pudiese demostrarse que está basada en criterios ideológicos debería entenderse como contraria tanto a esta libertad, la libertad ideológica, como a la libertad de expresión. La tutela de los derechos de terceros parece ser, en este sentido, el criterio que ha de regir la censura por parte de la administración de aquellos comentarios o entradas con los que los ciudadanos intervengan en sus páginas web ${ }^{76}$.

Del análisis de la doctrina judicial del government speech podemos sacar otra conclusión relevante, que es la de que la Corte Suprema ha puesto su atención en el contenido del discurso pero no en la propia forma de este discurso. Como hemos visto, sobre el concepto de government speech subyace la idea de que el Estado no puede cumplir con sus funciones de gobierno desde la neutralidad o la asepsia ideológica de su discurso, sino que está obligado a discriminar entre opciones ideológicas a la hora de hacer política. Ahora bien, el problema está en aquella escenificación del discurso estatal que no puede entenderse necesaria para llevar a cabo una determinada política de gobierno, sino que está destinada simplemente a provocar una adhesión emocional a las opciones ideológicas del gobierno. Un discurso gubernamental, podríamos decir, en el que la transparencia se confunde con la publicidad o la propaganda, y en el que se utiliza el propio "prestigio» que tiene lo público frente a los ciudadanos para defenestrar determinadas opciones privadas dentro de la comunidad política. Como puede apreciarse, esta crítica está en sintonía con esa idea de Political Establishment Clause que apelaba a una mínima neutralidad estatal, siquiera simbólica, como presupuesto para la propia legitimidad del sistema democrático. Aceptando que necesariamente el Estado tiene que poder "hablar políticamente», la doctrina del government speech tendría como tarea pendiente profundizar en los requisitos formales requeridos para la

76 Véase, en extenso, Rollnert Liern (2013: en especial, 154-162). 
protección del discurso gubernamental. Como ha apuntado algún autor, parece razonable que solo pueda beneficiarse de ese fuero de impunidad que presta la doctrina del government speech aquel discurso estatal de naturaleza puramente cognitiva, vinculado al ejercicio de sus competencias institucionales, pero no aquel de carácter ornamental, capcioso, manipulador o propagandístico, que persiga una suerte de seducción emocional de los ciudadanos (Bezanson, 2010: 812-817). Del mismo modo, visto desde la óptica de nuestro ordenamiento, creo que resulta importante diferenciar los ámbitos donde la información pública no es sino una actuación administrativa del Estado, vinculada a servicios públicos (Ituren Oliver, 2014), y por lo tanto, sometida a parámetros jurídicos de neutralidad y objetividad de una forma estricta, de aquellos otros que son manifestación de una decisión propiamente política y, por lo tanto, de la que necesariamente va a poder deducirse un discurso parcial desde el punto de vista ideológico no susceptible de control judicial en base a la idea de neutralidad estatal.

Una cuestión diferente es la del posible control judicial del discurso estatal ofensivo o discriminatorio, digamos del government hate speech. Aquí, sin duda, se hacen evidentes las particularidades del ordenamiento estadounidense con respecto a nuestra cultura jurídica, donde las constituciones incorporan valores sustantivos que implican -incluso en un ordenamiento abierto y personalista como el español — un cierto grado de militancia constitucional que delimita la propia comprensión del derecho a la libertad de expresión y sus límites. En cualquier caso, debe insistirse que la doctrina del government speech protege el discurso gubernamental no por su dignidad sino por su valor democrático. Es decir, la Corte Suprema en ningún momento entiende que el Estado sea titular del derecho a la libertad de expresión, sino simplemente que cumple una función institucional por definición ideologizada y por lo tanto no parcial. En este sentido, en ningún caso resulta trasladable al discurso gubernamental la doctrina general elaborada por la Corte Suprema sobre el hate speech, como todo el mundo sabe, muy deferente hacia la libertad de expresión. Ni el Estado es titular de este derecho ni su discurso posee un valor específico a la hora de contribuir al free market of ideas propio de una sociedad democrática. En realidad, desde la perspectiva del discurso del odio, lo que caracteriza al discurso estatal frente al privado es su potencial lesivo, ya que, a diferencia del de cualquier ciudadano, este dispone de unas herramientas de difusión específicas, y en cierta medida, de una presunción de veracidad y de un prestigio, que le hace más eficiente a la hora de dañar el estatuto moral de aquellos a los que denigra (Norton, 2004: 175-185). Por esta razón, no deja de llamar la atención la irrelevancia que tuvo para la Corte, en el litigio sobre la exhibición de banderas confederadas en las matrículas de estado de Texas, el argumento del daño moral que este símbolo de connotaciones supremacistas 
podía provocar en los ciudadanos. Una irrelevancia que nos lleva a pensar que en el ordenamiento americano podría considerarse legítimo un discurso gubernamental con estas connotaciones odiosas. A este respecto, creo que esta deferencia democrática hacia el discurso político gubernamental en tanto portavoz de un discurso mayoritario no es viable en ordenamientos como el español, donde, por un lado, la cuestión de los límites oponibles al discurso del odio no se afronta desde la idea de la casi incondicional posición preferente de la libertad de expresión, y, sobre todo, donde los poderes públicos actúan dentro de un marco constitucional que los vincula de forma expresa con determinados valores y principios constitucionales (Teruel, 2016).

Como hemos visto, el concepto de government speech ha adquirido una relevancia judicial determinante en muy distintas áreas, hasta el punto de ser una categoría central en el derecho constitucional norteamericano. A este respecto, las prevenciones de ciertos sectores académicos acerca de la su proyección ${ }^{77}$ adquieren fundamento propio si tomamos en cuenta algunos ejemplos de cómo, a través de esta categoría, la Corte ha interpretado el grado de discrecionalidad del que disfrutan las instituciones públicas para restringir el discurso de sus funcionarios cuando estos pongan en cuestión el relato que una determinada administración haya querido $\operatorname{trazar}^{78}$. Especialmente llamativa es la conclusión a la que llega la Corte en Garcetti v. Ceballos ${ }^{79}$, donde la mayoría de los jueces consideran que las sanciones impuestas a un ayudante del fiscal de distrito por haber elaborado una memoria crítica con una investigación policial en curso no podían considerarse contrarias a la libertad de expresión garantizada por la Primera Enmienda, dado que al ser directrices internas de un determinado departamento administrativo, eran expresión del discurso gubernamental. Para la Corte las restricciones de la libertad de expresión que traen causa en directivas administrativas «no infringen ningún derecho de los que estos mismos empleados disfrutarían como ciudadanos privados». Como señalara el juez Souter en su voto particular contrario al fallo de la mayoría, esta sentencia vendría a confirmar cómo la colonización por parte de la doctrina del government speech ${ }^{80}$ de diversos ámbitos judiciales ha derivado en una suerte de teoría de la impunidad del Estado en el ámbito de sus competencias,

77 Una proyección que, como hemos visto, se hace únicamente sobre la base del elemento objetivo de si se trata o no de un ámbito donde el Estado actúa dentro de sus managerial domains, y sin considerar, por lo tanto, la incidencia que las restricciones que este imponga pueden tener sobre ciertas libertades.

78 Para una crítica extensa de esta deriva jurisprudencial, puede verse, entre otros, Norton (2009: en especial, 58-60).

79 Garcetti v. Ceballos, 547 U.S. 410 (2006).

80 Garcetti v. Ceballos, 547 U.S. 410, 437 (2006). 
frente a las exigencias derivadas de libertades constitucionales básicas como, en este caso, la libertad investigadora o académica (Nahmod, 2008: 54).

Desde luego, no es difícil concluir que la proyección judicial de la doctrina del government speech ha ido demasiado lejos a la hora de extender el ámbito de inmunidad de las instituciones estatales. Sin embargo, el concepto jurídico de government speech, lejos de ser una categoría inútil o prescindible ${ }^{81}$, tiene el atractivo de haber puesto en pie una respuesta judicial a una cuestión inherente a cualquier democracia pluralista, como es la de qué alcance tiene para el Estado la exigencia constitucional de neutralidad. Partiendo de una realidad ineludible dentro de un sistema democrático, como es la de la parcialidad política de las instituciones electas, la Corte Suprema ha afirmado el principio de que gobernar es elegir y, por lo tanto, situar al Estado en una posición no equidistante entre diferentes puntos de vista. No es posible, en este trabajo, abordar en profundidad el contraste de este concepto con la idea de neutralidad política del Estado que puede deducirse de la jurisprudencia constitucional española y de nuestra propia legalidad. Sin embargo, en un ordenamiento como el español, donde la Constitución vincula a los poderes públicos activamente con la igualdad, la idea de government speech debe ser leída con necesarios matices. El gobierno, en tanto expresión de una mayoría ideológica, decidirá parcialmente sus políticas públicas, pero, en cualquier caso, no podrá hacerlo con total desprecio hacia el compromiso constitucional con la igualdad que la Constitución impone precisamente como presupuesto participativo de los ciudadanos. En nuestro ordenamiento, podríamos decir, existe una vinculación conceptual entre neutralidad e igualdad, hasta el punto de que, el juicio sobre la neutralidad de una política pública se va a proyectar a través del propio juicio de igualdad.

En definitiva, y por concluir, la idea de government speech alude para nosotros a la discrecionalidad que tiene el gobierno para atender a distintas finalidades a la hora de diseñar sus políticas, e impone, cuando estas finalidades sean cuestionadas desde la perspectiva de la igualdad, una cierta deferencia hacia su legitimidad y razonabilidad, fundada en el propio principio democrático, pero no su inmunidad jurídica. La rotunda afirmación de la Corte Suprema norteamericana de que nada en la Constitución impide la parcialidad ideológica del gobierno es, por lo tanto, en gran medida extrapolable a cualquier forma de gobierno constitucional, si bien, en un ordenamiento,

81 Probablemente ha sido el profesor Steven G. Gey quien más ha insistido en que sería preferible prescindir de este concepto, dada la forma en que ha sido proyectado por la Corte Suprema, si bien el propio autor no deja de reconocer que el fundamento teórico del mismo es incuestionable (Gey, 2010). 
como el español, donde existe un compromiso específico con la igualdad ${ }^{82}$, no solo el proceso político sino también los jueces podrán determinar jurídicamente la responsabilidad del gobierno, no por su falta de neutralidad ideológica, algo que es consustancial a sus funciones, sino por la ausencia de una finalidad legítima, o por la carencia de razonabilidad o proporcionalidad en las diferenciaciones de trato que establezcan ciertas políticas públicas.

\section{Bibliografía}

Alcacer Guirao, R. (2015). Víctimas y disidentes. El «discurso del odio» en EE. UU. y Europa. Revista Española de Derecho Constitucional, 103, 45-86.

Ardia, D. S. (2010). Government speech and online forums: First Amendment limitations on moderating public discourse on Government websites. Brigham Young University Law Review, 1981-1945.

Bezanson, R. P. (2010). The manner of Government speech. Denver University Law Review, 87 (4), 809-819.

- (2013). Art and Freedom of Speech. Chicago: Illinois University Press.

Blocher, J. (2011). Viewpoint Neutrality and Government Speech. Boston College Law Review, 52, 595-767.

Caruso, C. (2013) La libertá de expressione in azione. Contributo a una teoria constituzionale del discurso public. Bolonia: Bolonia University Press.

Constant, B. (2013). Una Constitución para la república de los modernos (fragmentos de una obra abandonada sobre la posibilidad de una Constitución republicana para un gran pais). Estudio preliminar y notas de María Luisa Sánchez-Mejía. Estudio de contextualización de Eloy García. Madrid: Tecnos.

Corbin, C. M. (2008). Mixed speech: when speech is both private and Governmental. New York University Law Review, 83, 101-189.

Dan-Cohen, M. (1984). Decision rules and conduct rules on acoustic separation in Criminal Law. Harvard Law Review, 97, 625-676. Disponible en: https://doi.org/10.2307/1340892.

82 Más desde argumentos morales que sobre la base de la propia Constitución, Owen Fiss es de los pocos autores que ha defendido de forma inequívoca una comprensión del «gobierno como patrón» vinculada a la remoción de obstáculos que impidan la participación y la igualdad material de ciertos colectivos. Para Fiss: «the revenues collected by the state constitute a public resource, to be used for public purposes, and I can think of no higher purpose for these funds than the preservation of democracy, bringing before the public viewpoints and options that otherwise might be slighted or ignored. Government subsidies, whether they be for the arts or education, should not be used to reinforce the prevailing orthodoxy, but rather to further the sovereignty of the people by provoking and stirring public debate, so that we may live as we do because we want to, not because the familiar is all we know or can imagine» (1991: 2106). 
DeNigris C. G. (2010). When Leviathan speaks: Reining in the Government-Speech Doctrine through a new and restrictive approach. American University Law Review 60, 133-170.

De Wolfe Howe, M. (1965). The garden and the wilderness: Religion and Government in American Constitutional History. Chicago: University of Chicago Press.

Esteve Pardo, J. (2013). La nueva relación entre Estado y sociedad: aproximación al trasfondo de la crisis. Madrid: Marcial Pons.

Fiss, O. (1991). State Activism and Censorship. Yale Law Journal, 100 (7), 2087-2106. Disponible en: https://doi.org/10.2307/796816.

Frank, J. P. (1940). Constitutional Law. Validity of Statutes restricting picketing and related activities. Wisconsin Law Review, 1940, 271-285.

Garry, P. M. (2009). Pleasant Grove City v. Summum: The Supreme Court finds a public display of the Ten Commandments to be permissible Government Speech. Cato Supreme Court Review, 2009, 271-294.

Gey, S. G. (2010). Why should the First Amendment protect Government speech when the Government has nothing to say? Iowa Law Review, 95, 1259-1332.

Hale, R. L. (1935). Unconstitutional conditions and Constitutional rights. Columbia Law Review, 35 (3), 321-359. Disponible en: https://doi.org/10.2307/1116396.

Hamilton, A., Madison, J. y Jay, J. (2003). The Federalist Papers. New York: Signet Classics.

Ituren Oliver, A. (2014). Derechos de los ciudadanos a recibir información por parte de la administración y obligaciones de los poderes públicos. En A. Boix y J. M. Vidal (coords.). La nueva regulación del audiovisual: medios, derechos y libertades (pp. 237-246). Cizur Menor: Aranzadi.

Kagan, E. (1992). The changing faces of First Amendment neutrality: R. A. V. v. St. Paul, Rust v. Sullivan, and the problem of content-based under inclusion. Supreme Court Review, 1992, 29-77. Disponible en: https://doi.org/10.1086/scr.1992.3109667.

- (1996). Private speech, public purpose: The role of Governmental motive in First Amendment doctrine. University of Chicago Law Review, 63, 413-517. Disponible en: https://doi.org/10.2307/1600235.

Kamenshine, R. D. (1979). The First Amendment's implied political establishment clause. CaliforniaLaw Review, 67, 1054-1153.Disponibleen:https://doi.org/10.2307/3480009.

Levinson, S. (1995). They whisper: Reflections on flags, monuments, and State holidays, and the construction of social meaning in a multicultural society. Chicago-Kent Law Review, 70, 1079-1119.

Michelman, F. J. (1969). On protecting the poor through the Fourteenth Amendment. Harvard Law Review, 83, 7-59. Disponible en: https://doi.org/10.2307/1339772.

Nahmod, S. (2008). Academic freedom and the Post-Garcetti Blues. First Amendment Law Review, 7, 54-75.

Norton, H. (2009). Constraining public employee speech: Government's control of its workers' speech to protect its own expression. Duke Law Journal, 59 (1), 1-68. (2004). Not for attribution: Government's interest in protecting the integrity of its own expression. University of California Davis Law Review, 37, 1317-1352.

- (2004). The equal protection implications of Government's hateful speech. William and Mary Law Review, 54, 159-2013. 
- (2015). Government Speech and political courage. Stanford Law Review Online, 68, 61-67.

Park D. W. (2010). Government speech and the public forum: A clash between democratic and egalitarian values. Gonzalez Law Review, 45, 113-148.

Porras Nadales, A. (2014). La acción de gobierno. Madrid: Trotta.

Post, R. (2005). Compelled subsidization of speech: Johanns v. Livestock Marketing Association. Supreme Court Review, 2005, 194. Disponible en: https://doi.org/10.1086/655190.

Revenga Sánchez, M. (2015). Los discursos del odio y la democracia adjetivada: tolerante, intransigente, ¿militante? En M. Revenga Sánchez (dir.). Libertad de expresión y discursos del odio (pp. 15-32). Alcalá de Henares: Universidad Alcalá de Henares; Defensor del Pueblo.

Rodríguez-Izquierdo Serrano, M. (2013). Internet entre otros medios o las distinciones mediáticas del Tribunal Supremo de los EE. UU. En L. Corredoira y L. Cotino Hueso (dirs.). Libertad de expresión e información en Internet. Amenazas y protección de los derechos personales (pp. 99-118). Madrid: Centro de Estudios Políticos y Constitucionales.

Rollnert Liern, G. (2013). La neutralidad ideológica del Estado en las redes sociales. En L. Corredoira y L. Cotino Hueso (dirs.). Libertad de expresión e información en Internet. Amenazas y protección de los derechos personales (pp. 143-164). Madrid: Centro de Estudios Políticos y Constitucionales.

Schmitt, C. y Kelsen H. (2009). La polémica Schmitt/Kelsen sobre la justicia constitucional: el defensor de la Constitución versus ¿quién debe ser el defensor de la Constitución? Estudio preliminar de Giorgio Lombardi. Madrid: Tecnos.

Shiffrin, S. (1980). Government Speech. UCLA Law Review, 27, 565-655.

Sullivan, K. M. (1991). Artistic freedom, public funding and the Constitution. En S. Benedict (ed.). Public money and the muse. Essays on Government Funding for the arts, The American Assembly. New York: W. W. Norton.

Sullivan, K. M. y Feldman, N. (2013). First Amendment Law. Foundation Press.

Teruel Lozano, G. M. (2016). La luchas del Derecho contra el negacionismo: una peligrosa frontera. Estudio constitucional de los limites penales a la libertad de expresión en ordenamiento abierto y personalista. Madrid: Centro de Estudios Políticos y Constitucionales.

Tribe, L. (1978). Toward a metatheory of free Speech. Southwester University Law Review, $10,237-246$.

Troy, D. (2005). Do we have a beef with the Court? Compelled commercial speech upheld, but it could have been worse. Cato Supreme Court Review, 2004, 125-157.

Vázquez Alonso, V. J. (2014). Welfare State and Judicial Review. Aproximación a una teoría «posible» del Estado social en el federalismo. Teoría y Realidad Constitucional, 34, 505.

- (2015). ¿Por qué la religión es constitucionalmente diferente? Anuario de Derecho Eclesiástico del Estado, 31, 137-196.

Waldron, J. (2012). The harm in hate speech. Cambridge: Harvard University Press. Disponible en: https://doi.org/10.4159/harvard.9780674065086.

Xiang, L. (2013). Hacktivism and the First Amendment: Drawing the line between cyber protests and crime. Harvard Journal of Law and Technology, 27 (1), 302-330.

Yudof, M. G. (1979). When the Government speech: Toward a Theory of Government Expression and the First Amendment. Texas Law Review, 57, 863-918.

- (1983). When Government Speech: Politics, Law, and Government Expression in America. Berkeley, Los Angeles, London: University of California Press. 